Swedish Dental Journal, Supplement 220, 2011

\title{
MARIA PIGG
}

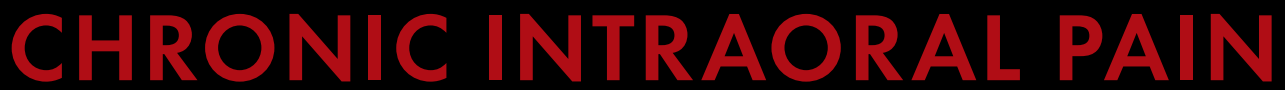

- Assessment of diagnostic methods and prognosis
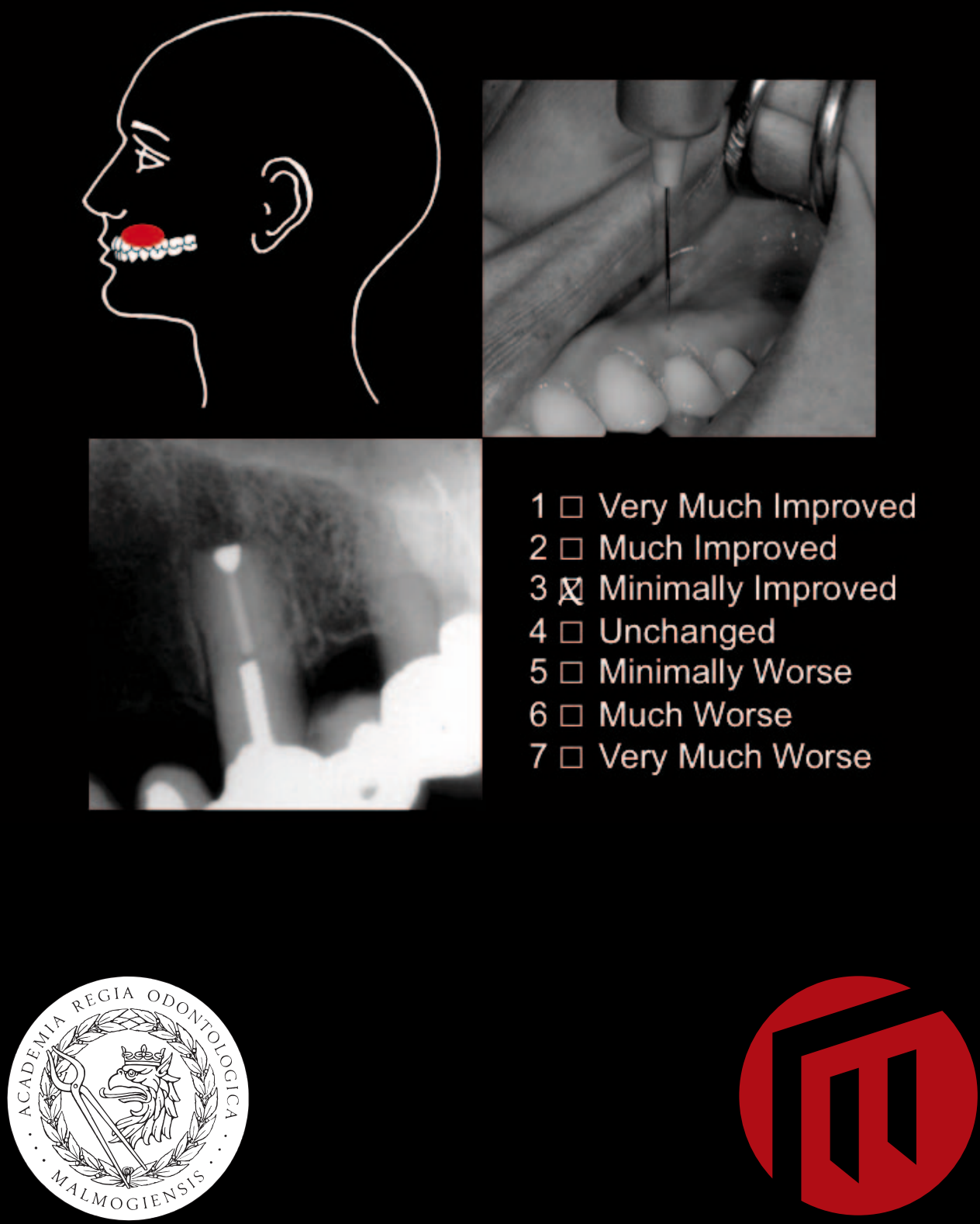

Swedish Dental Journal, Supplement 220, 2011

(C) Copyright Maria Pigg, 2011

ISBN 978-91-7104-387-0

ISSN 0348-6672

Holmbergs, Malmö 2011 


\section{MARIA PIGG \\ CHRONIC INTRAORAL PAIN}

- Assessment of diagnostic methods and prognosis

Department of Endodontics and Department of Stomatognathic Physiology Faculty of Odontology, Malmö University Malmö, Sweden 
The summary of this publication is also available at www.mah.se/muep

Please visit! 


\section{CONTENTS}

ABSTRACT ................................................... 7

POPULÄRVETENSKAPLIG SAMMANFATTNING

(SUMMARY IN SWEDISH) ...................................... 9

PREFACE ........................................................ 11

THESIS AT A GLANCE .................................... 12

ACRONYMS AND DEFINITIONS ............................ 13

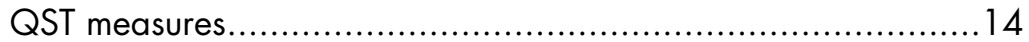

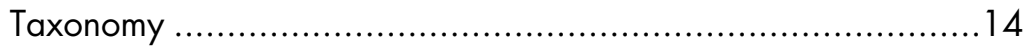

INTRODUCTION .................................................. 16

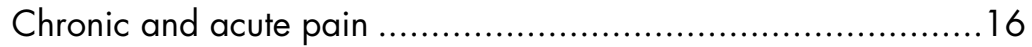

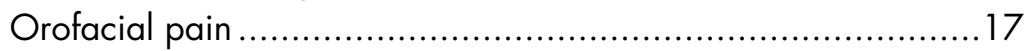

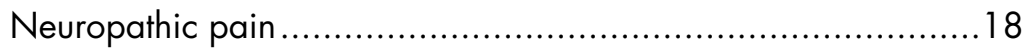

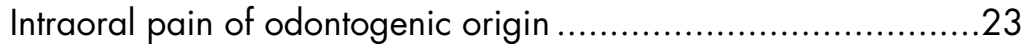

Intraoral pain of nonodontogenic origin ................................24

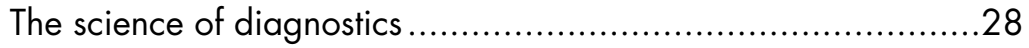

Diagnostic tests in tooth pain investigation ............................29

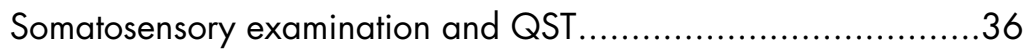

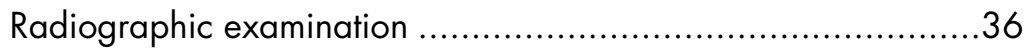

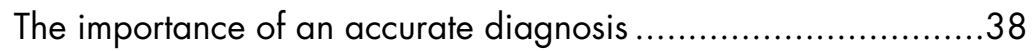

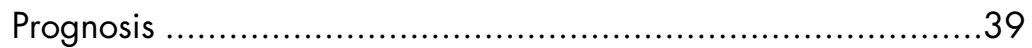

OBJECTIVES .................................................... 40

HYPOTHESES .............................................. 41

MATERIALS AND METHODS ................................. 42

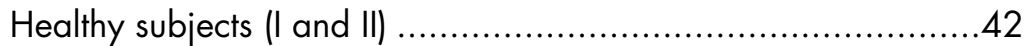

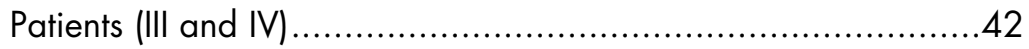

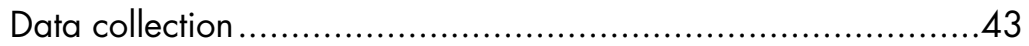

Clinical examination (III and IV) .....................................44 
Somatosensory examination and diagnostic testing (I, II, IV) ..... 44

Radiographic examination (III)........................................... 48

Self-report measures (III and IV) ......................................... 48

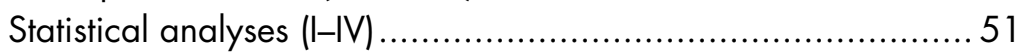

Informed consent and ethical approval (I-IV) ...........................5 53

RESULTS ................................................. 54

Characteristics of intraoral thermal thresholds (I) .....................54

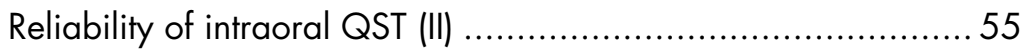

$\mathrm{CBCT}$ and conventional image assessments in patients with

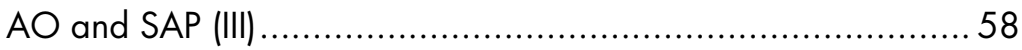

Prognosis and prediction of outcome in AO (IV) ..................... 59

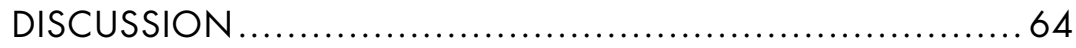

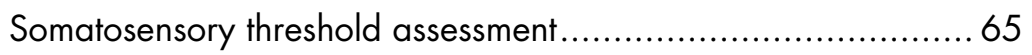

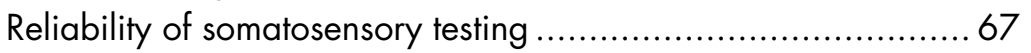

Radiographic examination in atypical odontalgia...................68

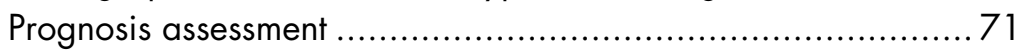

CONCLUSIONS, CLINICAL IMPLICATIONS,

AND FUTURE WORK PLAN ............................... 77

AUTHORS' CONTRIBUTION .................................... 80

ACKNOWLEDGEMENTS ..................................... 81

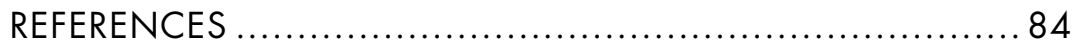

PAPERS I-IV ..................................................... 93 


\section{ABSTRACT}

The overall goal of this thesis was to broaden our knowledge of chronic intraoral pain. The research questions were:

- What methods can be used to differentiate inflammatory, odontogenic tooth pain from pain that presents as toothache but is non-odontogenic in origin?

- What is the prognosis of chronic tooth pain of nonodontogenic origin, and which factors affect the prognosis?

Atypical odontalgia $(\mathrm{AO})$ is a relatively rare but severe and chronic pain condition affecting the dentoalveolar region. Recent research indicates that the origin is peripheral nerve damage: neuropathic pain. The condition presents as tooth pain and is challenging to dentists because it is difficult to distinguish from ordinary toothache due to inflammation or infection. $\mathrm{AO}$ is of interest to the pain community because it shares many characteristics with other chronic pain conditions, and pain perpetuation mechanisms are likely to be similar.

An AO diagnosis is made after a comprehensive examination and assessment of patients' self-reported characteristics: the pain history. Traditional dental diagnostic methods do not appear to suffice, since many patients report repeated care-seeking and numerous treatment efforts with little or no pain relief. Developing methods that are useful in the clinical setting is a prerequisite for a correct diagnosis and adequate treatment decisions.

Quantitative sensory testing (QST) is used to assess sensory function on skin when nerve damage or disease is suspected. A variety of stimuli has been used to examine the perception of, for 
example, touch, temperature (painful and non-painful), vibration, pinprick pain, and pressure pain. To detect sensory abnormalities and nerve damage in the oral cavity, the same methods may be possible to use.

Study I examined properties of thermal thresholds in and around the mouth in 30 pain-free subjects: the influence of measurement location and stimulation area size on threshold levels, and time variability of thresholds. Thresholds for cold, warmth and painful heat were measured in four intraoral and two extraoral sites. Measurements were repeated 3 times over 6 weeks, using four sizes of stimulation area $\left(0.125-0.81 \mathrm{~cm}^{2}\right)$. The threshold levels were highly dependent on location but less dependent on measuring probe size and time variability was small, and this knowledge is important for the interpretation of QST results.

Study II applied a recently developed standardized QST examination protocol (intended for use on skin) inside the oral cavity. Two trained examiners evaluated 21 pain-free subjects on three occasions over 1-3 weeks, at four sites - three intraoral and one extraoral. Most tests had acceptable reliability and the original test instruments and techniques could be applied intraorally with only minor adjustments.

Study III examined the value of cone-beam computed tomography $(\mathrm{CBCT})$ in pain investigations. Twenty patients with $\mathrm{AO}$ and 5 with symptomatic apical periodontitis (inflammatory tooth pain) participated. The results indicate that when $A O$ is suspected, addition of CBCT can improve the diagnostic certainty compared to sole use of periapical and panoramic radiographs, especially because of the superior ability of CBCT to exclude inflammation as the pain cause.

Study IV assessed the long-term prognosis of AO, and analyzed potential outcome predictors. A comprehensive questionnaire including validated and reliable instruments was used to gather data on patient and pain characteristics and pain consequences from 37 patients in 2002 and 2009. Thirty-five percent of the patients reported substantial overall improvement at follow-up, but almost all still had pain of some degree after many years. The initial high level of emotional distress was unchanged. Low baseline pain intensity predicted improvement over time. 


\section{POPULÄRVETENSKAPLIG SAMMANFATTNING (SUMMARY IN SWEDISH)}

Det övergripande målet med avhandlingen var att öka vår förståelse av kronisk smärta i munnen. Tre delarbeten syftar till att undersöka och utveckla diagnosmetoder för att särskilja tandsmärta av olika ursprung, och det fjärde delarbetet undersöker långtidsprognosen för atypisk tandsmärta samt prognospåverkande faktorer.

Atypisk odontalgia $(\mathrm{AO})$, eller atypisk tandsmärta är ett allvarligt och kroniskt men relativt sällsynt smärttillstånd som uppträder $\mathrm{i}$ munhålans betandade område. Mycket tyder på att orsaken är skada på sensoriska nervceller, och bör betecknas neuropatisk smärta eller nervsmärta. Tillståndet yttrar sig som smärta $\mathrm{i}$ en tand eller $\mathrm{i}$ området där en tand har suttit, och är svårt att särskilja ifrån ”vanlig tandvärk" utlöst av inflammation eller infektion. AO liknar andra kroniska smärttillstånd på många sätt och det är troligt att samma eller liknande mekanismer underhåller smärtan.

Diagnosen ställs efter noggrann värdering av undersökningsfynd och patientens beskrivning av smärtsymptom och smärthistorik. Tandläkarens sedvanliga undersökningsmetoder förefaller inte tillräckliga; många patienter med $\mathrm{AO}$ beskriver upprepat vårdsökande och ett flertal behandlingsförsök med ringa eller helt utebliven smärtlindring. Det är angeläget att utveckla diagnosmetoder för att säkrare ställa rätt diagnos och därmed fatta riktiga behandlingsbeslut. 
Kvantitativ känselundersökning (QST) används på hud för att mäta känselfunktion när man misstänker nervskada eller sjukdom i nervsystemet, som ofta medför förändrad känseluppfattning. En rad stimuli används för att undersöka känslighet för $t$ ex beröring, temperatur, vibration, sticksmärta och trycksmärta. För att påvisa känselförändring och nervskada i munhålan borde det vara möjligt att använda samma undersökningsmetodik.

I delarbete I studerades temperaturtrösklar i och omkring munnen. Trösklar för kyla, värme och smärtsam värme mättes på smärtfria försökspersoner 3 gånger under 6 veckor. Mätningar gjordes även med varierande storlek på mätinstrumentets stimuleringsyta. Temperaturkänsligheten påverkades mycket av mätlokalisation men betydligt mindre av stimuleringsytans storlek, och tidsvariationen var liten. Kunskapen har betydelse för tolkning av mätresultat vid känselundersökning.

I delarbete II användes ett standardiserat testprotokoll för kvantitativ känselundersökning, nyligen utvecklat för att användas på hud. Två undersökare mätte känsel- och smärttrösklar i mun och ansikte på smärtfria försökspersoner vid tre tillfällen, och de flesta ingående testen uppvisade acceptabel tillförlitlighet. Metoden kan därmed användas i framtida forskning och på sikt möjligen även vid diagnostik.

Delarbete III undersökte värdet av volymtomografiundersökning (CBCT) i smärtutredning. Resultaten tyder på att volymtomografi kan öka den diagnostiska säkerheten vid misstänkt atypisk tandsmärta, eftersom metoden är överlägsen övriga röntgenmetoder för att påvisa inflammatoriska förändringar i käkbenet.

Delarbete IV undersökte långtidsprognosen för atypisk tandsmärta. Genom ett omfattande frågeformulär med validerade och tillförlitliga instrument och mätskalor insamlades patient- och smärtkarakteristika från 37 patienter med AO år 2002 och 2009. $35 \%$ av patienterna angav väsentlig förbättring över tid, men nästan alla hade fortfarande smärtor $\mathrm{i}$ någon grad, och depressiva symptom förekom i oförändrat hög utsträckning. Låg ursprunglig smärtintensitet innebar större sannolikhet för en förbättrad situation på lång sikt. 


\section{PREFACE}

This thesis is based on the following articles, which are referred to in the text by their roman numerals:

I

Pigg M, Svensson P, List T. Orofacial thermal thresholds: time-dependent variability and influence of spatial summation and test site. J Orofac Pain 2011; 25(1):39-48.

II

Pigg M, Baad-Hansen L, Svensson P, Drangsholt M, List T. Reliability of intraoral quantitative sensory testing (QST). Pain 2010; 148: 220-6.

III

Pigg M, List T, Petersson K, Lindh C, Petersson A. Diagnostic yield of conventional radiographic and cone-beam computed tomographic images in patients with atypical odontalgia. Int Endod J 2011; 44(12):1092-101.

IV

Pigg M, Svensson P, Drangsholt M, List T. Longterm prognosis of atypical odontalgia. A 7-year prospective study. Submitted for publication, October 2011.

The articles are reprinted with kind permission from the copyright holders: Blackwell Quintessence Publishing Co. Inc. (I), the International Association for the Study of Pain (II), and John Wiley \& Sons, Inc. (III). 


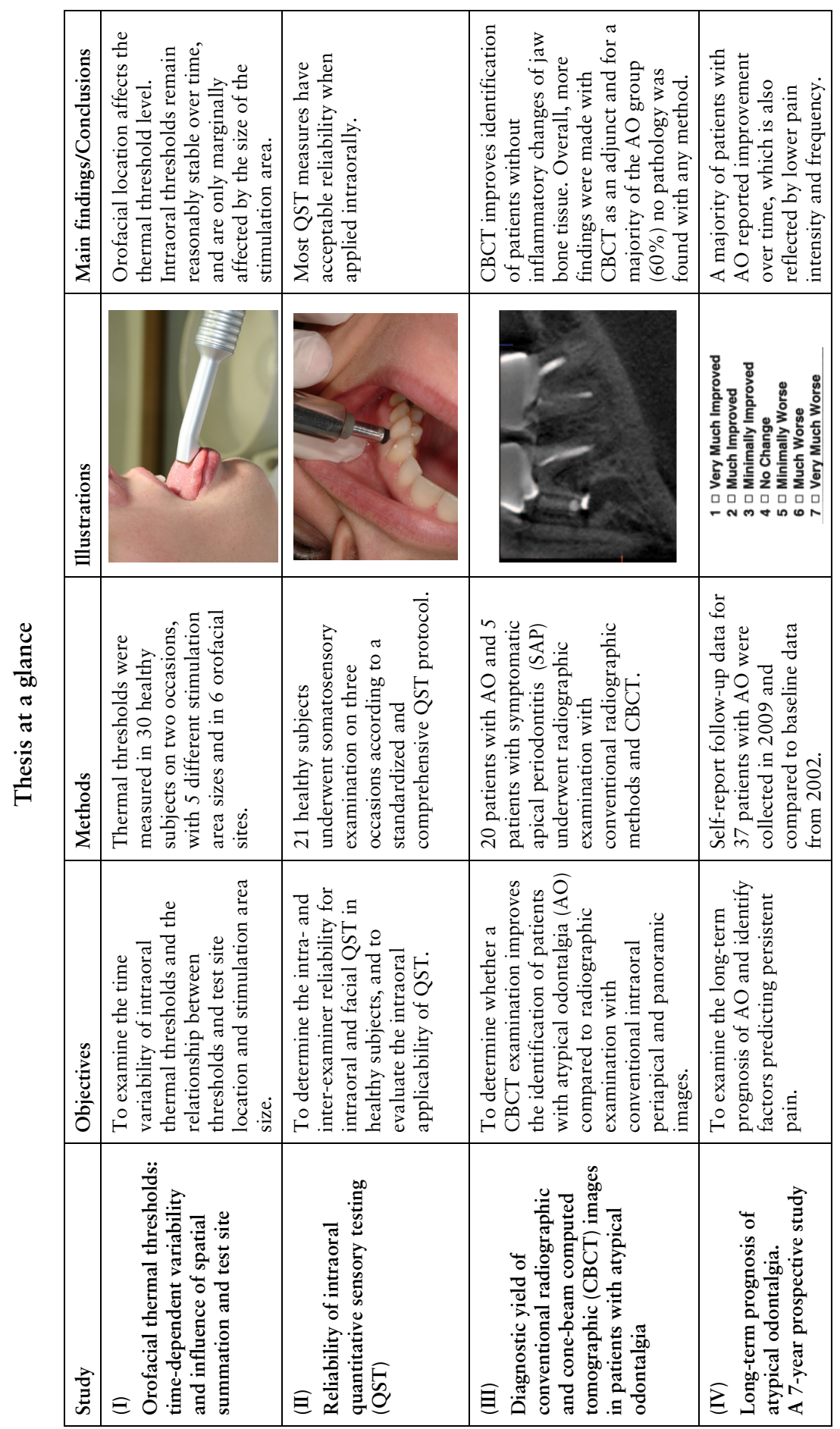




\section{ACRONYMS AND DEFINITIONS}

$\begin{array}{ll}\text { AFP } & \text { Atypical facial pain } \\ \text { AO } & \text { Atypical odontalgia } \\ \text { BMS } & \text { Burning mouth syndrome } \\ \text { CBCT } & \text { Cone-beam computed tomography } \\ \text { CPI } & \text { Characteristic pain intensity } \\ \text { DFNS } & \text { German Research Network on Neuropathic Pain } \\ \text { GCPS } & \text { Graded chronic pain severity } \\ \text { IASP } & \text { International Association for the Study of Pain } \\ \text { ICC } & \text { Intraclass correlation coefficient } \\ \text { IMMPACT } & \text { Initiative on Methods, Measurement, and Pain } \\ & \text { Assessment in Clinical Trials } \\ \text { JFLS } & \text { Jaw functional limitation scale } \\ \text { NRS } & \text { Numerical rating scale (0-10) } \\ \text { PDAP } & \text { Persistent dento-alveolar pain disorder } \\ \text { PGIC } & \text { Patients' global impression of change scale } \\ \text { QST } & \text { Quantitative sensory testing } \\ \text { RDC/TMD } & \text { Research diagnostic criteria for TMD } \\ \text { RCT } & \text { Randomized controlled trial } \\ \text { SAP } & \text { Symptomatic apical periodontitis } \\ \text { SCL-90R } & \text { Symptom checklist 90 revised } \\ \text { SF-36 } & \text { Short-form health survey, 36 items } \\ \text { STARD } & \text { Standards for Reporting of Diagnostic Accuracy } \\ \text { TMD } & \text { Temporomandibular disorders }\end{array}$




\section{QST measures}

$\begin{array}{ll}\text { CDT } & \text { Cold detection threshold } \\ \text { WDT } & \text { Warmth detection threshold } \\ \text { CPT } & \text { Cold pain threshold } \\ \text { HPT } & \text { Heat pain threshold } \\ \text { PHS } & \text { Paradoxical heat sensation (on cold stimulus) } \\ \text { TSL } & \text { Thermal sensory limen } \\ \text { MDT } & \text { Mechanical detection threshold } \\ \text { MPT } & \text { Mechanical pain threshold } \\ \text { MPS } & \text { Mechanical pain sensitivity } \\ \text { DMA } & \text { Dynamic mechanical allodynia } \\ \text { WUR } & \text { Wind-up ratio } \\ \text { PPT } & \text { Pressure pain threshold } \\ \text { VDT } & \text { Vibration detection threshold }\end{array}$

\section{Taxonomy}

\section{Nociceptive pain}

Pain that arises from actual or threatened damage to non-neural tissue and is due to the activation of nociceptors (IASP pain taxonomy 2011).

\section{Neuropathic pain}

Pain caused by a lesion or disease of the somatosensory nervous system (IASP pain taxonomy 2011).

\section{Allodynia}

Pain due to a stimulus that does not normally provoke pain (IASP pain taxonomy 2011).

\section{Hyperalgesia}

Increased pain from a stimulus that normally provokes pain (IASP pain taxonomy 2011). 


\section{Dysesthesia}

An unpleasant abnormal sensation, whether spontaneous or evoked (IASP pain taxonomy 2011).

\section{Paresthesia}

An abnormal sensation, whether spontaneous or evoked (IASP pain taxonomy 2011).

\section{Spatial summation}

The ability of the nervous system to integrate nociceptive input from large areas. The sensory threshold and perceived intensity are affected by increasing the stimulation area, manifested as decreased pain threshold and increased pain intensity (Nie et al. 2009).

\section{Temporal summation}

The ability of the nervous system to integrate repetitive nociceptive input, i.e. increasing pain perception to repetitive stimulation at the same intensity (Nie et al. 2009).

\section{Peripheral sensitization}

Increased responsiveness and reduced threshold of nociceptive neurons in the periphery to the stimulation of their receptive fields (IASP pain taxonomy 2011).

\section{Central sensitization}

Increased responsiveness of nociceptive neurons in the central nervous system to their normal or subthreshold afferent input (IASP pain taxonomy 2011). 


\section{INTRODUCTION}

\section{Chronic and acute pain}

The International Association for the Study of Pain currently defines pain as 'an unpleasant sensory and emotional experience associated with actual or potential tissue damage, or described in terms of such damage' (IASP pain taxonomy 2011). Nearly every human being has some personal experience of pain; it is one of the basic bodily sensations. While acute pain could be described as a survival mechanism, alerting us to impending or ongoing tissue damage and invoking a withdrawal reflex, chronic pain is more complex and has no clear-cut physiological value.

The concept of chronic pain embraces several different meanings depending on the situation: it is a complex, multi-dimensional condition. One popular definition is 'pain that extends beyond the expected period of healing', which usually refers to pain persisting for more than 3-6 months. Chronic pain may be associated with a chronic disease, such as rheumatoid arthritis or multiple sclerosis, and also with less well-defined disorders, such as irritable bowel syndrome, back pain, fibromyalgia, chronic headache, and TMD. Another type of chronic pain is pain that persists long after initial tissue damage has healed and occurs when plastic changes in the nervous system have become permanent.

Chronic pain is a very different condition from pain associated with acute tissue damage. Why some patients develop chronic pain conditions and others do not is not fully known, but genetic factors may be involved (Diatchenko et al. 2005). Psychological factors 
seem to be intimately involved in the individual's perception of pain, the transition of acute pain into chronic pain, and the maintenance of chronic pain (Turk 1999). Social and cultural contexts shape patients' perceptions and responses to pain, and psychosocially dysfunctional individuals appear to be less able to develop effective coping strategies (Dworkin and Massoth 1994). The biopsychosocial model describes chronic pain as a multidimensional phenomenon, focusing on perceived illness rather than disease. Three main aspects of pain can thus be distinguished: the sensory (physiological), the affective (emotional and motivational), and the evaluative (cognitive) dimensions (Linton and Skevington 1999).

World-wide, chronic pain is one of the most common health problems today and affects approximately $10-30 \%$ of the adult population-a recent systematic review found a prevalence of $19 \%$ for moderate to severe general (non-cancer) chronic pain in Europe (Reid et al. 2011). The consequences of chronic pain are enormous costs in healthcare expenses, lost income, and lost productivity. Many studies have shown chronic pain to have a detrimental effect on patient-perceived health status, quality of life, activities of daily life and mental health (Breivik et al. 2006; Collett 2011). A substantial proportion of non-cancer chronic pain patients report not receiving pain treatment, and many others consider their pain treatment inadequate (Bekkering et al. 2011).

The most commonly reported non-cancer chronic pain disorders are musculoskeletal pain, neuropathic pain, fibromyalgia, osteoarthritis, and rheumatoid arthritis (Reid et al. 2011).

\section{Orofacial pain}

One of the most common locations for pain is the orofacial area. Orofacial pain is a term referring to oral pain, dental pain, and pain in the face above the neck, anterior to the ears and below the orbitomeatal line (Zakrzewska and Hamlyn 1999). In an epidemiological study including 45,711 households in the US, $21 \%$ of the population had experienced orofacial pain of some kind during the last 6 months. The pain was described as toothache, 
oral sores, jaw joint pain, face or cheek pain, or burning mouth, and around one-fifth of the patients had experienced more than one pain symptom, or a combination of symptoms. Toothache when biting or chewing (or pain perceived as coming from a tooth) was by far the most frequently reported symptom, reported by 12\% (Lipton et al. 1993).

In the dental office, a common reason for seeking emergency care is pain. Most orofacial pain conditions are of an acute, nociceptive character-such as pain from dental hypersensitivity, reversible and irreversible pulpitis, apical periodontitis and dental traumabut others, while still mainly nociceptive in character, are more chronic-such as myofascial pain in the masticatory system and arthralgia of the temporomandibular joint. Still other pain conditions are neuropathic, such as trigeminal and pretrigeminal neuralgia, glossopharyngeal neuralgia, and posttraumatic neuralgia after injury or surgical trauma. Idiopathic tooth pain or atypical odontalgia ( $\mathrm{AO}$ ); burning mouth syndrome; headache presenting as dental pain; referred pain from the masticatory system, from neck and shoulder structures, or from ongoing angina pectoris; systemic disease; maxillary sinusitis; and psychosocial or behavioral factors are other possible causes of pain, and for various reasons, a correct diagnosis may be difficult (Svensson and Sessle 2004).

\section{Neuropathic pain}

Neuropathic pain was recently redefined by the IASP as a clinical description of 'pain caused by a lesion or disease of the somatosensory nervous system' (IASP pain taxonomy 2011). The term 'lesion' is commonly used when diagnostic investigations (e.g., imaging, neurophysiology, biopsies, and laboratory tests) reveal an abnormality or when there was obvious trauma. The term 'disease' is commonly used when the underlying cause of the lesion is known (e.g., stroke, vasculitis, diabetes mellitus, or genetic abnormality). Lesions or diseases of the neural tissues can occur either in the CNS or peripherally, and do not always cause pain. The prevalence of peripheral neuropathy is reported to be $2.4 \%$ in the general population, rising to $8 \%$ in ages above 55 years (Cruccu and Truini 2010). 
In the diagnostic descriptions and criteria for various disease entities, some are based mainly on clinical presentation (e.g., trigeminal neuralgia) and others on history (e.g., postherpetic neuralgia). Clinical decision-making thus requires knowledge of neuroanatomy and -physiology, a thorough review of patientreported history and symptoms, and a comprehensive clinical examination with relevant and targeted clinical diagnostic testing, supplemented by laboratory tests if needed (Haanpää et al. 2011). Figure 1 depicts the recommended diagnostic process for patients with suspected neuropathic pain (Treede et al. 2008).

Figure 1. Grading system for neuropathic pain diagnosis (modified from Treede et al. 2008)

Working hypothesis: possible neuropathic pain, if:

- Pain distribution is neuroanatomically plausible

and

- History suggests a relevant lesion or disease

Confirmatory tests:

A: Negative or positive sensory signs, confined to the innervation territory of the lesioned nervous structure (bedside sensory examination or QST)

B: Diagnostic test confirming lesion or disease

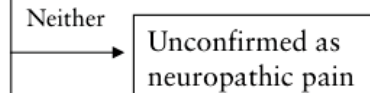
explaining neuropathic pain (neuroimaging, neurophysiological testing etc)

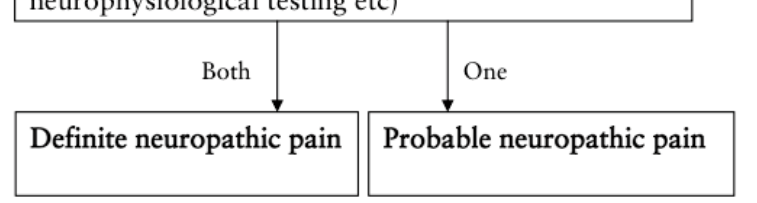

The diagnosis relies heavily on evidence of a damaged somatosensory system, represented by altered somatosensory function. The patient's report of abnormal sensations, paresthesia or dysesthesia is one leg of this. The other is the clinician's 'bedside' examination of sensory function: a qualitative (or semiquantitative) assessment of nerve fiber function using simple and commonly available tools to examine touch (A $\beta$-fibers), cold (A $\delta$ - 
fibers) and pain (A $\delta$ - and C-fibers) perception. Figure 2 depicts equipment for cutaneous qualitative sensory testing.

Figure 2. Equipment for extraoral qualitative sensory examination.

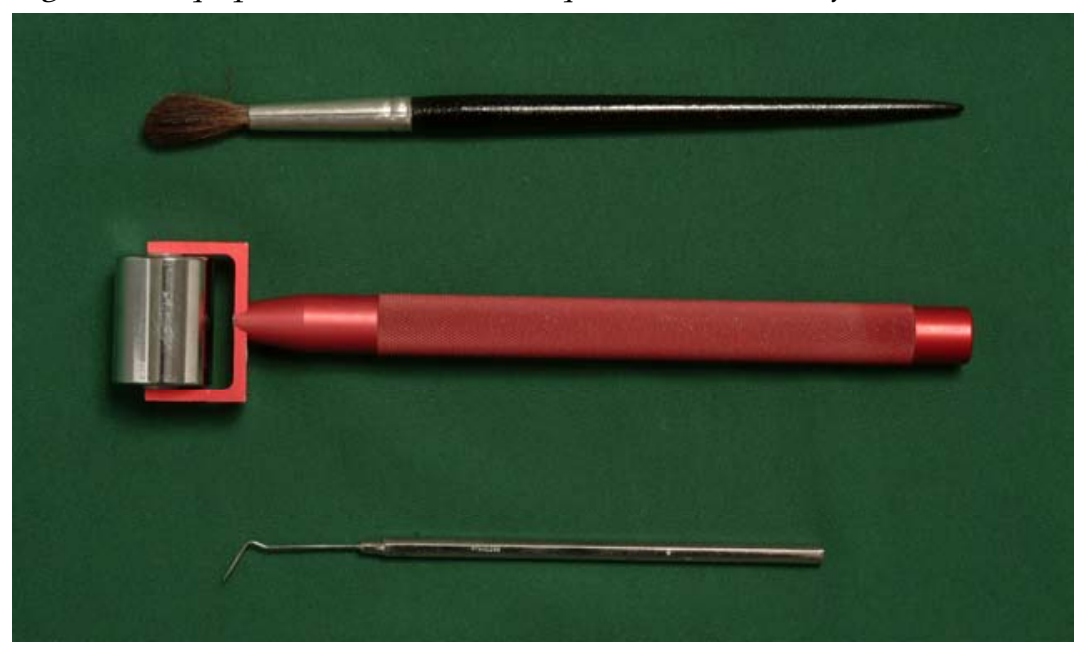

New guidelines on how to assess neuropathic pain in general were presented in 2004, and these have been updated (Cruccu et al. 2004; Cruccu et al. 2010; Haanpää et al. 2011). No criterion standard (or gold standard) for diagnosing neuropathic pain exists (no clinical or laboratory test can distinguish between a neuropathy without pain and a painful neuropathy), so the aim should be to confirm the diagnosis of an underlying neuropathy that could rationally explain the pain problem reported by the patient. Using the same standards, recommendations for methods to assess neuropathic pain in the trigeminal area are under development (Svensson et al. 2004; Svensson et al. 2011).

Laboratory tests for diagnosing peripheral neuropathy and small fiber neuropathy in general include electroneuromyography (large fiber), microneurography, laser-evoked potentials, functional brain imaging (PET and fMRI), and skin biopsy (epidermal innervation).

Quantitative sensory testing (QST) is a more comprehensive clinical method of assessing sensory nerve function than qualitative bedside testing. Until lately, a major drawback of QST has been a 
lack of standardization in the choice of test modalities and in test performance recommendations, resulting in a lack of reference data for normal nerve function and lack of knowledge on the somatosensory characteristics of various conditions. In the last decade, however, substantial progress has been made in this field, and the validity and reliability of QST on cutaneous sites is now approaching the standard where it may be considered a clinically useful test method and not just a research tool. A few studies examining the orofacial area have also been presented (Juhl et al. 2008; List et al. 2008; Pfau et al. 2009). Recently, an international task force established by the IASP Special Interest Group on Orofacial Pain (SIG-OFP) presented guidelines and recommendations for assessment of somatosensory function in patients with orofacial pain (Svensson et al. 2011).

In particular, a comprehensive QST protocol developed by the German Research Network on Neuropathic Pain (DFNS) has gained substantial interest in the neuropathic pain community (Rolke et al. 2006b). The DFNS protocol includes functional assessment of the sensory fibers: $A \beta, A \delta$, and $C . A \beta$ function is evaluated by measuring detection thresholds for mechanical touch and vibration, $\mathrm{A} \delta$ and $\mathrm{C}$ function by measuring thermal detection and pain thresholds (cold, warmth, cold pain and heat pain) and mechanical pain thresholds for pinprick and pressure stimuli. In addition, signs of central sensitization are assessed by examining the occurrence of (i) paradoxal heat sensations on cold stimulation, (ii) temporal summation to repeated pinprick pain stimuli, and (iii) allodynia to a light stroking mechanical stimulus. One objection to somatosensory testing has been that it can be time consuming, which would limit its clinical usefulness. The DFNS protocol makes a comprehensive evaluation of somatosensory function possible in about 30 minutes per examined site, which is considered clinically feasible.

QST results can be transformed into Z-scores to describe a patient's sensory profile. Z-transformation (Figure 3) of each sensory modality into a standard normal distribution allows the patient to be compared to a control group with normal sensory 
function in a standardized way, independent of the stimulus modality's unit of measurement.

Figure 3. Z-transformation of QST parameters.

$$
\mathrm{Z} \text {-score }=\frac{\mathrm{X}_{\text {individual patient }}-\text { group mean } \text { controls }_{\text {controls }}}{\mathrm{SD}_{\text {con }}}
$$

The individual Z-score for each modality is then compared to a control group mean at $95 \% \mathrm{CI}\left(\right.$ mean $\left._{\text {controls }} \pm 1.96 \mathrm{SD}_{\text {controls }}\right)$

According to this concept, a positive Z-score denotes increased sensitivity (gain of function) and a negative Z-score, decreased sensitivity (loss of function) in units of standard deviation (SD) of the control group (Rolke et al. 2006b). Figure 4 is an example of sensory profiles based on Z-scores.

Only the presence of signs of a disturbed somatosensory function, revealed through diagnostic testing, do not justify use of 'neuropathic' in the diagnosis, since diagnostic tests commonly yield inconclusive or inconsistent data. Somatosensory function may be altered in other pain conditions as well, such as acute nociceptive pain and functional pain, due to the physiological plasticity of the nervous system (Latremoliere and Woolf 2009). 
Figure 4. Sensory profiles of three patients with AO, based on Ztransformation of QST modalities (Z-scores)

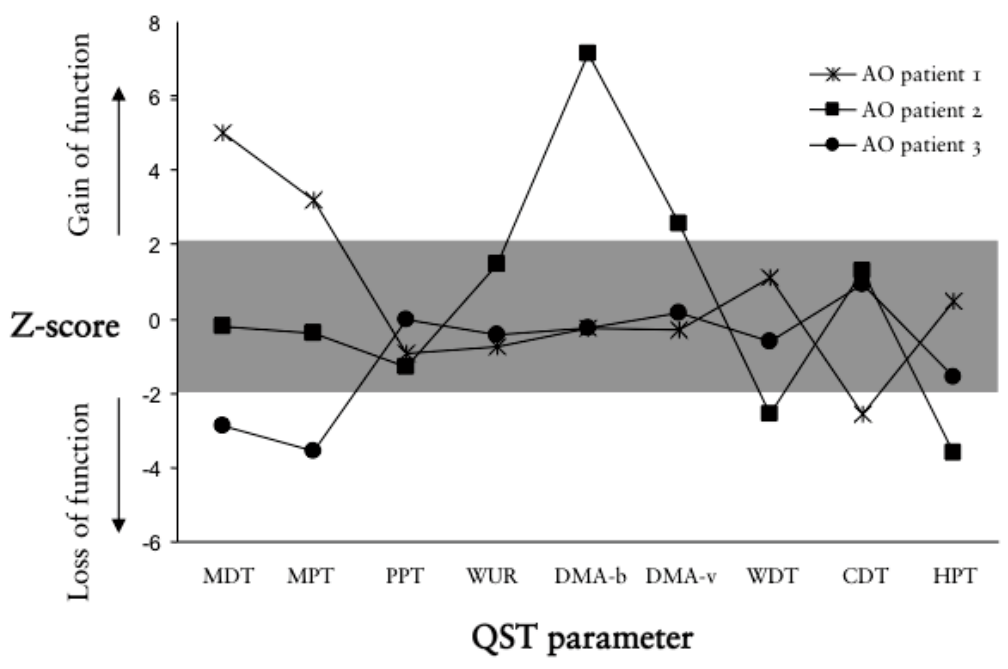

(From List et al. 2008, modified with permission)

\section{Intraoral pain of odontogenic origin}

Pain perceived as coming from one or more teeth in a region can be either odontogenic or non-odontogenic in origin. The most common by far is odontogenic tooth pain. Figure 5 lists possible origins of pain presenting as toothache.

Typical dental or dentoalveolar pain can present with a variety of symptoms ranging from intermittent and slight discomfort provoked by chewing, biting or tooth brushing to a continuous, spontaneous, severe, and highly disabling pain that affects many aspects of daily life. Pulpal and periapical inflammations are the most common causes of tooth pain. About one-third of all dental emergencies are reported to be endodontic, and about $90 \%$ of emergency appointments with pain as a symptom are prompted by pain from the dental pulp or the periapical region (Rossman et al. 2006). One review article reported the prevalence of dental pain to be $7-66 \%$ depending on the defining criteria used and the population studied (Pau et al. 2003). 
Figure 5. Origins of tooth pain.

\begin{tabular}{|c|c|}
\hline Odontogenic & Non-odontogenic \\
\hline Dental hypersensitivity & $\begin{array}{c}\text { Musculoskeletal origin } \\
\text { myofascial }\end{array}$ \\
\hline Symptomatic pulpitis & Neuropathic origin \\
\hline \multirow{7}{*}{$\begin{array}{l}\text { Symptomatic apical periodontitis } \\
\text { Symptomatic marginal periodontitis } \\
\text { Pericoronitis }\end{array}$} & $\begin{array}{l}\text { trigeminal neuralgia } \\
\text { glossopharyngeal neuralgia } \\
\text { atypical odontalgia }\end{array}$ \\
\hline & Neurovascular origin \\
\hline & $\begin{array}{l}\text { migraine } \\
\text { cluster headache }\end{array}$ \\
\hline & $\begin{array}{c}\text { Inflammatory conditions } \\
\text { sinusitis }\end{array}$ \\
\hline & Systemic disorders \\
\hline & $\begin{array}{l}\text { cardiac pain } \\
\text { herpes zoster } \\
\text { sickle cell anemia } \\
\text { neoplastic disease } \\
\text { multiple sclerosis }\end{array}$ \\
\hline & $\begin{array}{l}\text { Psychogenic origin } \\
\text { somatoform pain disorder }\end{array}$ \\
\hline
\end{tabular}

In inflammatory conditions, pain is induced through activation of normally functioning sensory nerve fibers; the pain is nociceptive in character. The affected peripheral nerve fibers include primary afferent neurons of the dental pulp, the gingiva and the periodontal ligament.

\section{Intraoral pain of nonodontogenic origin}

Besides tooth pain of odontogenic causes, the dentist is sometimes confronted with tooth pain caused by pathological processes outside the tooth (Fig. 5). The diagnostic process involves (i) a comprehensive evaluation of the patient's description of symptoms and of events preceding the pain problem, (ii) clinical observations, and (iii) the results of clinical and radiographic tests and examinations. Most times, findings are straightforward and the dentist is able to arrive at a diagnosis quickly and with reasonable certainty. Other times, the differential diagnosis can be quite challenging: the clinical presentation may be complex and test 
results inconclusive. In such cases, a conservative approach is often recommended and invasive treatment should be avoided until the diagnosis is more certain. For effective pain management, an accurate diagnosis should precede any treatment.

Atypical odontalgia (AO), also known as neuropathic tooth pain, phantom tooth pain (PTP), and persistent idiopathic facial pain (PIFP), is perhaps the most difficult to distinguish from toothache of dental origin. An international consensus collaboration, organized by the International RDC-TMD Consortium, recently introduced a new classification system for orofacial pain taxonomy based on ontological principles and adhering to the Ontology of General Medical Science (OGMS) guidelines. The collaboration examined $\mathrm{AO}$ as an example condition, and reviewed and revised the diagnostic criteria. Persistent dento-alveolar pain disorder (PDAP) was suggested as the new term, but it has not yet gained widespread acceptance (Nixdorf et al. 2011). AO has been described as tooth-related pain or pain located at a site where a tooth was extracted, in absence of clinical or radiographic evidence of tooth pathology or other relevant hard or soft tissue pathology explaining the pain (Melis et al. 2003). Pain has been ongoing for at least 6 months, is not paroxysmal in character, and is continuous or present during most of the day. Sleep is usually unaffected (Woda and Pionchon 1999). All adult ages and both sexes can be affected, but with a preponderance of women 45-60 years (List et al. 2007; Melis et al. 2003).

A recent systematic review found the prevalence of persistent pain after endodontic treatment to be $5.3 \%$, with higher report quality studies suggesting $>7 \%$ (Nixdorf et al. 2010a). Studies examining nonsurgical and surgical endodontic treatment and retreatment were included. A meta-analysis of nine prospective studies reporting details on pain cause estimated the prevalence of nonodontogenic tooth pain as $3.4 \%$, likely including patients with $\mathrm{AO}$ (Nixdorf et al. 2010b).

Patients with AO have often received multiple unsuccessful irreversible treatments aimed at pain relief (List et al. 2007; 
Marbach and Raphael 2000). The etiology and mechanisms of pain development and pain perpetuation are still being debated. Deafferentation of primary afferent trigeminal nerve fibers has been suggested as the cause.

The theory that $\mathrm{AO}$ is neuropathic in origin and that neural mechanisms are involved in pain maintenance has been explored in many studies over the last decade. The evidence includes:

- Pain onset is frequently reported in relation to an invasive dental or surgical procedure (such as endodontic treatment, endodontic surgery, tooth extraction, orthognathic surgery, facial fractures, dental implant placement, and dental injections), in other words, a known or plausible trauma to trigeminal sensory fibers (List et al. 2007; Turp 2001).

- Animal studies show that loss of tooth pulp in an inflamed environment produces a neuronal response with derangement of the periodontal plexus and axonal sprouting or neuroma formation (Holland 1995).

- The human blink reflex (a trigeminofacial brainstem reflex) is delayed and reduced in patients with AO compared to painfree control subjects, which may indicate impaired nerve function. Also, the blink reflex was altered on the painful and the non-painful side, suggesting involvement of central mechanisms in these patients (Baad-Hansen et al. 2006b).

- Increased sensitivity to topical application of capsaicin occurs in patients with AO compared to pain-free controls. The change in sensitivity is present on both painful and non-painful sides, indicating central sensitization (Baad-Hansen et al. 2006a; Baad-Hansen et al. 2007).

- Studies on QST report sensory abnormalities in patients with $\mathrm{AO}$, in response to both mechanical and thermal stimuli. Signs of hypersensitivity as well as hyposensitivity in the pain area occur, but results are partly contradictory between studies 
(Lang et al. 2005; List et al. 2008), perhaps due to differences in assessment technique, test site (intraoral vs. extraoral), or test group inclusion criteria or to true heterogeneity in somatosensory characteristics in the patient group. A standardized assessment method with confirmed reliability is likely to give better information on somatosensory function in these patients and allow comparison between pain conditions.

- Application of a painful cold stimulus in the pain area produced a prolonged pain sensation (aftersensation) in patients with AO compared to controls. Moreover, the effect also occurred on the non-painful side, indicating involvement of central mechanisms (Zagury et al. 2011).

What makes differential diagnosis between odontogenic, inflammatory tooth pain and nonodontogenic, neuropathic tooth pain particularly challenging may be a combination of several factors:

- The conditions share many clinical characteristics and can be similar in clinical presentation.

- Toothache of odontogenic origin is much more common than neuropathic tooth pain, and is indeed the most likely explanation for pain localized to a tooth. It is familiar to the dentist, while pain conditions with lower prevalence are generally less familiar and therefore less easily suspected.

- The diagnostic work-up commonly used in pain investigations is primarily designed to detect signs of inflammation; in practice, test results indicating pathology are usually interpreted as inflammation, although alternative interpretations exist.

- A patient presenting with persistent pain is often emotionally affected by the pain and presents a stressful situation to the dentist. To help the patient and remove the pain without delay, the dentist may base the treatment decision on less conservative diagnostic criteria and, for example, initiate 
endodontic treatment despite absence of convincing signs of irreversible pulpal disease, thus accepting the risk of overdiagnosis (Reit and Petersson 2010)

- There is a lack of diagnostic tests able to reliably distinguish nociceptive tooth pain from neuropathic tooth pain.

- Dental emergency care in general is very efficient. Quick and efficient pain relief of toothache is usually possible, and most patients have come to expect this. But if the dentist cannot effect immediate pain relief due to, for example, diagnostic complexity, the patient is disappointed and feels the dentist has done something wrong. The patient may express a strong and urgent conviction of what is needed-endodontic treatment or extraction of the painful tooth-and seek care elsewhere until finding a dentist willing to provide this treatment; a behavior often referred to as "doctor shopping".

\section{The science of diagnostics}

Diagnostics is the collected information about a condition (the patient's story and clinical observations) that together with other information (e.g., knowledge of disease mechanisms and treatment efficacy) serves as the basis for a treatment decision. Diagnostic methods need to distinguish between health and disease, to evaluate degrees of disease, and to differentiate conditions from each other, making it possible to move forward in the process of clinical decision making (SBU, Swedish Council on Health Technology Assessment 2010). Making a diagnosis is often a complex task, and professionals will unavoidably vary in their decisions, depending on interpretation of clinical observations, level of knowledge, and personal experience, among other things.

The diagnostic process has sometimes been regarded more as an act of art than of science. But clinical reasoning can - and shouldbe described in scientific terms, and diagnostic procedures structured and compared according to scientific criteria, which is necessary when deciding the usefulness of a method in a particular 
situation. Some important properties of diagnostic tests are briefly outlined below.

Validity. The extent to which the test agrees with the "true" condition for which it is used as the diagnostic aid to identify.

Reference standard (criterion or gold standard). A reference test with optimal validity, used to evaluate other diagnostic tests.

Diagnostic accuracy. The extent to which a test correctly identifies what it is meant to identify; the overall agreement between the test and the reference standard.

Sensitivity and specificity. Two ways of expressing diagnostic accuracy. If the prevalence of the condition in the population is known, positive and negative predictive values can be calculated.

Reliability. The reproducibility or repeatability of a test; to what extent a test can be repeated with the same results by another examiner (inter-examiner reliability) or by the same examiner on another occasion (test-retest or intra-examiner reliability).

For many diagnostic tests in wide use clinically, these properties are not fully known. The Standards for Reporting of Diagnostic Accuracy (STARD) initiative is an effort to improve the reporting quality of studies on diagnostic accuracy (Bossuyt et al. 2003). Their checklist for study design and manuscript preparation allows (i) identification of possible sources of bias and (ii) evaluation of a test's usefulness in various circumstances.

\section{Diagnostic tests in tooth pain investigation}

While the pathological mechanisms of pulpal and periapical inflammation have been vigorously studied, the literature describes the scientific properties of clinical diagnostic testing methods less well. Simple psychophysical tests are often useful in the clinical situation, despite not being very standardized. Dichotomous outcomes (response or no response) are generally used as guidelines in assessing endodontic disease. 
Provocation of teeth and periapical tissues and pulpal sensibility assessment are common tests when endodontic disease is suspected. Accuracy-sensitivity and specificity-has been determined for some tests of pulp necrosis or presumed irreversible pulpitis (Table 1). The accuracy and variability of many tests are unknown, however, and test validity-to differentiate between pain conditions with similar presentation but of different origin-is often insufficiently examined. Tests applied in the diagnosis of a patient with toothache include:

- Mechanical provocation of teeth

Pain on percussion

Pain on apical palpation

Cusp loading

- $\quad$ Pulp testing

Cold stimulus

Heat stimulus

Electrical stimulus

- Diagnostic anesthesia

- Transillumination of natural teeth

- Provocation of referred pain

Palpation of the masticatory system

Neck examination

Thermal stimulation of teeth 
Table 1. Accuracy of intraoral diagnostic tests. IP: Irreversible pulpitis; PN: Pulp necrosis

\begin{tabular}{|c|c|c|c|c|c|}
\hline Test & Condition & Sensitivity & Specificity & $\begin{array}{l}\text { Predictive } \\
\text { values }\end{array}$ & Reference \\
\hline Percussion & $\begin{array}{l}\text { IP } \\
\text { or PN }\end{array}$ & $0.36-0.66$ & $0.68-0.92$ & $\begin{array}{l}+0.59-0.70 \\
-0.81-0.88\end{array}$ & $\begin{array}{l}\text { Hyman \& Cohen } \\
1984\end{array}$ \\
\hline $\begin{array}{l}\text { Palpation } \\
\text { (apical) }\end{array}$ & $\mathrm{PN}$ & $0.26-0.47$ & $0.77-0.90$ & $\begin{array}{l}+0.31-0.36 \\
-0.85-0.87\end{array}$ & $\begin{array}{l}\text { Hyman \& Cohen } \\
1984\end{array}$ \\
\hline $\begin{array}{l}\text { Cold } \\
\text { pulp test }\end{array}$ & $\mathrm{PN}$ & $0.68-0.83$ & $0.70-0.93$ & $\begin{array}{l}+0.33-0.92 \\
-0.81-0.94\end{array}$ & $\begin{array}{l}\text { Hyman \& Cohen } \\
1984 \\
\text { Petersson et al } \\
1999 \\
\text { Gopikrishna et al } \\
2007\end{array}$ \\
\hline $\begin{array}{l}\text { Heat } \\
\text { pulp test }\end{array}$ & $\mathrm{PN}$ & 0.41 & 0.48 & $+0.48-0.83$ & $\begin{array}{l}\text { Petersson et al } \\
1999\end{array}$ \\
\hline $\begin{array}{l}\text { Electrical } \\
\text { pulp test }\end{array}$ & $\mathrm{PN}$ & 0.72 & 0.93 & $+0.88-0.84$ & $\begin{array}{l}\text { Petersson et al } \\
1999\end{array}$ \\
\hline
\end{tabular}

In inflammatory tooth pain, increased sensibility is the result of a complex series of interactions. Mediators are synthesized and/or released, and they activate nociceptive fibers. The affected neurons in turn release neuropeptides, which increase the inflammation further (neurogenic inflammation) and sensitize the nociceptors, thereby reducing the threshold for pain on stimulation such as percussion.

In nerve damage, the mechanisms are less clear but likely involve both peripheral and central sensitization. Changes in the reactivity of the sensory nervous system may provide alternative interpretations of diagnostic test results, and failure to appreciate this may lead to an incorrect diagnosis. Alternative test interpretations and implications for differential diagnostic accuracy are described below. 


\section{Mechanical provocation of teeth}

Pain on percussion of a tooth is generally interpreted as presence of inflammation in the periapical tissues and considered a sign of either inflammation spread throughout the pulp (engaging the periodontium immediately apical to the tooth) or apical periodontitis. The inflammatory process also affects sensory nerves, and the pain threshold is lowered so that normally nonpainful stimuli elicit pain. Allodynia and hyperalgesia are clinical signs of peripheral sensitization of nociceptors and the changes subsequently induced in higher order neurons (Hargreaves et al. 1994).

In $\mathrm{AO}$, pain is often reported to increase on percussion of one or more teeth in the painful area (Merskey and Bogduk 1994). The usefulness of percussion testing in distinguishing between toothrelated pain conditions such as symptomatic pulpitis, symptomatic apical periodontitis, and neuropathic tooth pain is largely unknown.

Pain or tenderness on palpation of the region overlying the apex or apices of a tooth-a case of allodynia-is usually interpreted as presence of periapical inflammation subsequent to pulp necrosis. Patients with AO often report tenderness and increased pain on palpation of the painful region, including the periapical area (Graff-Radford and Solberg 1992; Merskey and Bogduk 1994). The validity of apical palpation to distinguish symptomatic apical periodontitis from neuropathic tooth pain has not been examined.

Cusp loading with a FracFinder, Tooth Slooth, or similar instrument aims to detect incomplete fractures and cracks in teeth by selectively inducing force in various areas of the tooth. Loading a cusp that has a crack usually produces a sharp sensation of pulpal pain in the vital tooth. Responses vary, depending on location and extension of the crack, and are more doubtful in rootfilled teeth. Teeth with symptomatic apical periodontitis are usually painful on biting (Tronstad 2009). Also in atypical odontalgia, AO pain often intensifies on biting and chewing (Melis 
et al. 2003), but the validity of the test to differentiate pain conditions is unreported.

\section{Pulp testing}

In the trigeminal area, pulp testing may be useful in distinguishing pulpal pain and pain from other conditions, such as referred pain (Gopikrishna et al. 2009). A normal response to pulp testing may eliminate pulpal pathology. Pulp testing is usually done by thermal or electrical provocation of the pulp through the hard tissues of the crown.

Cold stimulation of teeth (e.g., applying ice or ethyl chloride) is often done to test dental pulp vitality. Vital pulp usually responds to stimulation with mild to moderate pain sensation. The underlying mechanism may involve the hydrodynamic flow of dentinal fluid causing movement in odontoblast processes and activation of adjacent free nerve endings (Olgart 1986).

Allodynia to cold, such as increasing pain in cold or windy weather, is frequently reported in $\mathrm{AO}$, and cold stimulation of gingiva has elicited lingering pain in patients with $\mathrm{AO}$ (Zagury et al. 2011). Whether also responses to pulp cold testing can be altered in teeth in the painful region has not yet been examined.

Heat stimulation of teeth (heated gutta-percha) is sometimes used for vitality testing but mostly to provoke bouts of toothache in patients presenting with intermittent pain of suspected pulpal origin, to determine which tooth is responsible. The hyperalgesia and allodynia here are clinical signs of nociceptive fibers' increased and prolonged response to heat stimulation after sensitization by inflammatory mediators (Hargreaves et al. 1994). Whether heat stimulation of teeth can provoke or increase atypical tooth pain is unreported. Discomfort and increased pain on intake of hot food or drink is frequent in patients with pulpitis but has also been reported for AO (Merskey and Bogduk 1994).

Electrical stimulation of teeth (using an electronic pulp testing device) is frequently used to examine pulp vitality by testing the 
responsiveness of pulpal nerves to electrical stimulation. It is unknown whether response to electrical pulp testing of teeth in the painful region is altered when nerve function is impaired.

\section{Diagnostic anesthesia}

If the pain is continuous or at least ongoing at the time of examination, efforts to extinguish the symptoms may provide diagnostic guidance (Reit and Petersson 2010). Individual tooth anesthesia can help localize the painful tooth by determining whether local anesthesia eliminates the pain. This method is useful primarily in the maxilla; mandibular blocks are less selective. But there are drawbacks: successful analgesia usually points up the offending tooth, but pain relief may also be due to the placebo effect, and failure to produce analgesia may have several causes: insufficient dosage, erroneous injection technique, or presence of referred pain or non-odontogenic tooth pain. In $\mathrm{AO}$, diagnostic anesthesia was reported to produce pain relief in about half of the patients (List et al. 2006). Anesthetic agents are also used as pain treatment. In a study on trigeminal neuralgia, peripheral nerve blocks of $10 \%$ lidocaine produced pain relief in $34 \%$ of patients for 3-172 weeks. Responders to the lidocaine block had significantly lower pretreatment pain intensity and shorter pain duration than non-responders, possibly indicating mainly peripheral mechanisms for pain maintenance in patients where peripheral injections were effective (Han et al. 2008).

\section{Transillumination of natural teeth}

Optical testing can be helpful in detecting cracks and incomplete fractures in natural teeth. A strong, well-localized light (preferably fiberoptic) applied to the crown may help localize cracks and fractures since they block penetration of light through the tooth (Tronstad 2009).

Drawbacks to the test as a differential diagnostic aid include (i) depending on the location and extension, the crack may be difficult to detect; (ii) in restored teeth, cracks can often be seen under magnification (e.g., microscopic inspection) and may not necessarily be related to any symptoms; (iii) pain present in a 
cracked root-filled tooth is not easy to interpret; and (iv) the method is usually not helpful in crowned teeth.

\section{Provocation of referred pain}

Palpation of the masticatory muscles can also provoke pain in teeth. Pain is referred from the 'true' pain site (muscle fibers) to another peripheral site because first-order neurons from both regions converge onto the same central second-order neurons in the CNS. The pain is experienced as coming from a tooth, and palpation of the muscle site provokes increased local pain in the muscle and referred tooth pain (Okeson and Bell 2004). If masticatory muscle palpation provokes tooth pain, dental treatment will most likely not relieve the tooth pain since the pain probably originates in the masticatory muscles.

A neck examination yields information on mobility and range of movement of the neck and on musculoskeletal pain that may or may not be related to the tooth pain. Just as for the masticatory muscles, pain from the neck muscles may be referred to toothbearing areas through neural convergence (Simons et al. 1999). When increased tooth pain is provoked by neck manipulation, it is not unlikely that the origin of pain is to be found in neck structures, and dental treatment is thus not indicated.

Thermal stimulation of teeth with pulpitis frequently produces onset of pain. Due to neural convergence, both spontaneous and provoked pain can be perceived as coming from another tooth, on the ipsilateral side but often in the opposite jaw. Provocation test of suspected teeth then helps localize the offending tooth (Bender 2000).

Almost no single test is truly a differential diagnostic, because the result is rarely specific to any one condition. Lack of information on validity, suboptimal sensitivity and specificity as well as lack of standardization in testing procedures and equipment may limit the usefulness of a particular test. In intraoral pain investigations, multiple diagnostic tests are highly recommended, as well as considering alternative diagnoses. 
The differential diagnosis of persistent pain localized to a tooth or a tooth region may require development of more specific methods. Long-term, the goal is to apply diagnostic methods that will help clinicians distinguish neuropathic, nonodontogenic tooth pain from inflammatory, odontogenic tooth pain with greater certainty.

\section{Somatosensory examination and QST}

$\mathrm{AO}$ is suggested to be a neuropathic pain condition. To fulfill the diagnostic criteria for neuropathic pain, altered function in the sensory nervous system must be present and possible to demonstrate. Patients may describe abnormal sensations (paresthesia or dysesthesia) such as discomfort, numbness, tingling, tenderness, itching, feelings of hollowness, enlargement, or swelling of the tissues; pain elicited on chewing, tooth brushing or touching the painful area; and pain elicited on eating or drinking cold or hot food or beverages.

No clinical diagnostic method is currently able to objectively evaluate somatosensory function in the oral cavity. Qualitative and quantitative sensory testing procedures that are used on other body sites for suspected neuropathic pain may conceivably be useful intraorally. Prior to clinical use in pain investigations, testing methods in the orofacial area should be evaluated for reliability, validity and clinical feasibility. Studies I and II have taken the first steps toward this goal.

\section{Radiographic examination}

Radiographic visualization of inflammation signs is a common diagnostic method. Periapical bone destruction (or defect) is assessed as a surrogate measure for periapical disease. One study found that, for identifying periapical inflammation, intraoral periapical images had a sensitivity of 0.55 and a specificity of 0.98 ; panoramic images had a sensitivity of 0.28 and a specificity of 1.00. СBCT was the reference standard and the prevalence of periapical inflammation was estimated as $64 \%$ (Estrela et al. 2008). 
The low sensitivity of conventional radiographic images indicates a risk of false negative tests-failure to identify the disease. Sensitivity of CBCT is higher (in laboratory studies), but periapical bone destruction observed with CBCT has not been clearly correlated to histologically detected inflammation of human jaw bone tissue. Thus to what degree bone destruction observed with this method correlates with disease is unknown.

In patients with $\mathrm{AO}$ invasive treatment has usually been done, often repeatedly. This complicates the interpretation of any periapical findings. Periapical bone defects around apices of endodontically treated teeth may be present for considerable time without active disease, for example, during healing after endodontic treatment, after endodontic surgical interventions, and as residual defects in cortical bone (Christiansen et al. 2009). In such cases, a single radiographic examination is insufficient to diagnose ongoing disease; comparison over time is necessary, which is inconvenient when earlier radiographs are unavailable and the patient is in severe pain.

In addition, the conventional radiograph is a summation imageall structures present between the source of radiation and the sensor or film are reproduced at the same spot-thus the diagnostic information on whether a bone defect is truly localized around the apices of the suspected tooth is not clear. Another consequence is that structural noise may disturb reliable assessment of the periapical area; for example the zygomatic arch is often projected over the apices of the posterior maxillary teeth. Besides better visualization of the periapical area, CBCT may also yield information not found in the periapical image, such as additional roots, untreated root canals in endodontically treated teeth, and root perforations and fractures (Lofthag-Hansen et al. 2007).

The diagnostic output of a radiographic examination could be improved in several ways: (i) increasing the ability to detect disease, (ii) decreasing structural noise, and (iii) improving the ability to judge whether findings in the periapical region are related to periapical disease, through improved $3 \mathrm{D}$ discrimination of the 
image. CBCT is reported to be superior to intraoral periapical and panoramic radiography in all these respects, and study III examines the usefulness of CBCT for differential diagnosis of tooth pain.

\section{The importance of an accurate diagnosis}

The main reason why an accurate diagnosis is important is that the best treatment available for the condition can be provided as soon as possible, and ineffective or harmful treatment to the patient can be avoided.

Patients with chronic tooth pain are typically treated by general dentists and then referred to endodontic specialists, TMD specialists, or oral and maxillofacial surgeons when the pain appears to be treatment resistant. Repeated attempts at various dental treatments are made but prove ineffective, while more adequate treatment is postponed. A patient with $\mathrm{AO}$ consults on average 4-7 different professionals for the pain (List et al. 2007; Pfaffenrath et al. 1993); clear evidence of just how difficult it often is to find the accurate diagnosis and treatment. Case reports describe single patients having received multiple ortograde endodontic treatments and retreatments, endodontic surgical interventions and extractions for intractable pain (Marbach et al. 1982). Because pain due to endodontic disease and neuropathic tooth pain are perpetuated by different mechanisms, effective treatment will also differ.

Endodontic treatment aims mainly to remove the cause of pulpal or periapical inflammation, which is often microbial infection, and if necessary, also remove irreversibly inflamed pulp to promote preservation or restoration of healthy periapical conditions. Causal treatment normally resolves symptoms, and endodontic treatment (nonsurgical or surgical) or tooth extraction usually yields effective pain relief (Seltzer and Hargreaves 2002).

In neuropathic pain, symptoms are caused by abnormal function of the sensory nervous system. It may be impossible to restore normal function, so treatment must instead aim to reduce symptoms. In this case, further invasive dental treatment does not usually 
improve the patient's situation; on the contrary, many patients report increased or unchanged pain.

\section{Prognosis}

The prognosis for neuropathic tooth pain or AO has not been investigated in large, high-quality studies. The main reason for this may be that a large material is difficult to collect. The etiology of AO has long been debated, and diagnostic criteria have changed over time and are likely to change again. Reports of long-term outcome in patient cohorts with less specified pain conditions show that a majority of patients with chronic orofacial pain are still in pain many years after the pain investigation (Allerbring and Hägerstam 2004; Wolf et al. 2002).

From the patient's perspective, it would be helpful to know the long-term outcome-is this pain likely to go away or not? For professionals, better knowledge is needed of what factors are important to consider in assessing the prognosis. Study IV of this thesis investigates the long-term prognosis for $\mathrm{AO}$ in a prospective study of 46 patients, for whom various aspects of clinical and psychosocial character had been thoroughly examined previously, and thus establishes the accuracy of the diagnosis with reasonable certainty (List et al. 2006; List et al. 2007; List et al. 2008). 


\section{OBJECTIVES}

The general aims of this thesis were to (i) develop diagnostic methods for the investigation of persistent intraoral pain and (ii) assess the long-term prognosis and risk factors for persistent pain in $\mathrm{AO}$.

The specific aims of the studies on which this thesis is based were to:

- Investigate time-dependent variability and influence of test site and stimulation area size on orofacial thermal thresholds for warmth, cold, and painful heat (I).

- Investigate intra-examiner (test-retest) and inter-examiner reliability for intraoral and facial QST in healthy control subjects, and to evaluate the intraoral applicability of QST (II).

- Investigate whether the additional diagnostic yield of a CBCT examination over conventional intraoral periapical and panoramic radiographs in patients suspected of having $\mathrm{AO}$ improves the identification of $\mathrm{AO}$ (III).

- Examine the long-term prognosis of AO and identify factors predicting persistent pain in AO over 7 years (IV). 


\section{HYPOTHESES}

- Thresholds for perceived warmth, cold, and painful heat vary between different orofacial sites (I).

- Intraoral thermal thresholds and size of stimulation area are correlated (I).

- Intraoral thermal thresholds remain stable over a 6-week period (I).

- Intraoral and facial sensory threshold reliabilities (between and within examiners) are acceptable and of a similar magnitude (II).

- The additional information on anatomical structures in the pain area provided by CBCT examination-compared with conventional intraoral periapical and panoramic radiographs-improves the possibilities to identify AO (III).

- Self-report measures and clinical characteristics have predictive value for the long-term outcome of $\mathrm{AO}$ (IV).

- Patients with AO who show clinical signs of abnormal nervous function have a less favorable long-term prognosis (IV). 


\section{MATERIALS AND METHODS}

\section{Healthy subjects (I and II)}

Study I

Thirty young healthy subjects, 15 men and 15 women, participated. The subjects were recruited from among dental students at Malmö University. The inclusion criterion was good health with no orofacial pain complaints. The exclusion criterion was dental treatment scheduled for during the study.

Study II

Twenty-one healthy subjects, 13 women and 8 men, were included. The subjects were recruited from the staff at Malmö University's Dental School, or respondents to flyers and advertisement. The inclusion criterion was good health with no orofacial pain complaints; exclusion criteria were dental treatment scheduled for the time of the study and intake of medication during the time of the study (antidepressants, analgesics, or hypnotics).

\section{Patients (III and IV)}

Study III

Twenty patients with AO (18 women and 2 men) and 5 patients with symptomatic apical periodontitis (SAP, 3 women and 2 men) participated. All patients were recruited from the Departments of Stomatognathic Physiology or Endodontics or the Dental School Emergency Unit at Malmö University. The SAP group served as positive controls for the radiographic assessments, to ensure that 
conventional radiography and CBCT images would depict periapical bone destruction as expected.

The inclusion criterion for the $\mathrm{AO}$ group was continuous or recurrent pain located in a region where a tooth had been endodontically or surgically treated or extracted, with no pathological cause detectable in clinical or intraoral radiographic examinations and persisting for more than 6 months.

For the SAP group, the inclusion criterion was continuous or recurrent pain from a tooth that was diagnosed with apical periodontitis after clinical and intraoral radiographic examinations.

Exclusion criteria for both groups were trigeminal neuralgia, herpes zoster, maxillary sinusitis, cluster headache, and paroxysmal hemicrania.

\section{Study IV}

The study examined 46 patients diagnosed with AO, previously described in a study by List et al. 2007. In 2002, these patients were recruited from four orofacial pain clinics in Sweden (the Specialist Public Dental Service Clinics for Stomatognathic Physiology in Linköping, Kalmar and Jönköping, and the Department of Stomatognathic Physiology at Malmö University).

\section{Data collection}

Table 2 gives an overview of the type of data collected in the four studies. 
Table 2. Data collection study by study.

\begin{tabular}{lcccc}
\hline Study & I & II & III & IV \\
\hline Clinical examination & & & $X$ & $(X)$ \\
Somatosensory examination & $\mathrm{X}$ & $\mathrm{X}$ & & $(\mathrm{X})$ \\
Radiographic examination & & & $\mathrm{X}$ & \\
Self-report data & & $\mathrm{X}$ & $\mathrm{X}$ \\
\hline
\end{tabular}

\section{Clinical examination (III and IV)}

Study III

The clinical examination comprised a dental examination (assessment of pain location and pain on percussion or apical palpation, assessment of periodontal pocket depth, selective loading with a FracFinder, transillumination of natural teeth with an optical fiber [when possible], and sensibility testing of non-rootfilled teeth), an examination of the masticatory system (according to the RDC/TMD), and a head and neck examination.

\section{Study IV}

No clinical data were collected at follow-up, but baseline clinical data from 2002 were available and in part analyzed as possible predictors of pain resolution or persistence (marked with $[\mathrm{X}]$ in Table 2) . A thorough dental examination, an examination of the masticatory system according to the RDC/TMD, and a neurological examination had all been done as part of the pain investigation of these patients.

\section{Somatosensory examination and diagnostic testing (I, II, IV)} Assessment of thermal thresholds (I)

Cold detection thresholds (CDTs), warmth detection thresholds (WDTs), and heat pain thresholds (HPTs) were assessed at six sites: the mucosal side of the lower lip, the buccal gingiva adjacent to the first upper left premolar and the first lower left premolar, the tip of the tongue, the skin area just below the left eye, and an extra-trigeminal point on the hand. Threshold assessments were 
made using an MSA Thermotest (Modular Sensory Analyzer, SOMEDIC, Hörby, Sweden) with a $0.81-\mathrm{cm}^{2}$ contact surface intraoral probe. Baseline temperature was $37^{\circ} \mathrm{C}$ for intraoral and $32^{\circ} \mathrm{C}$ for extraoral sites. Cut-off temperatures were $10^{\circ} \mathrm{C}(\mathrm{CDT})$ and $51^{\circ} \mathrm{C}$ (WDT and $\mathrm{HPT}$ ). Temperature ramp (rate of temperature change) was $1^{\circ} \mathrm{C} / \mathrm{s}$. Subjects were instructed to press a stop button when the threshold was reached (i.e., when the soughtafter stimulus was perceived), thereby terminating stimulation.

At one intraoral site-the tip of the tongue-threshold measurements were also (i) performed with varying stimulation area size and (ii) repeated after 2 weeks and after 6 weeks.

(i) Plastic cover tips (Figure 6), successively reducing the size of contact area (between probe surface and oral mucosa) were manufactured for the intraoral thermode from 1-mm thick ethylene-propylene copolymer (thermal conductivity coefficient $0.12 \mathrm{~W} / \mathrm{m} \cdot \mathrm{K}$; Essix C+, Ortopro AB, Gothenburg, Sweden). Contact areas were $0.81 \mathrm{~cm}^{2}$ (uncovered $=$ no plastic tip), $0.50 \mathrm{~cm}^{2}, 0.28 \mathrm{~cm}^{2}, 0.125 \mathrm{~cm}^{2}$, and 0.00 $\mathrm{cm}^{2}$ (fully covered $=$ control). The purpose of this was to examine the influence of stimulation area size on threshold levels, and the occurrence of intraoral spatial summation (increasing stimulation area decreases the threshold level for when a stimulus is perceived).

(ii) Measurements with the $0.81 \mathrm{~cm}^{2}$ stimulation area were repeated after 2 weeks and after 6 weeks to examine the time variability of intraoral thermal thresholds.

Because the starting temperature was not the same for extra- and intraoral sites, delta values (deviation from starting temperature) were calculated and used in all comparisons between sites. 
Figure 6. Intraoral probe and plastic cover tips used to vary stimulation area size.

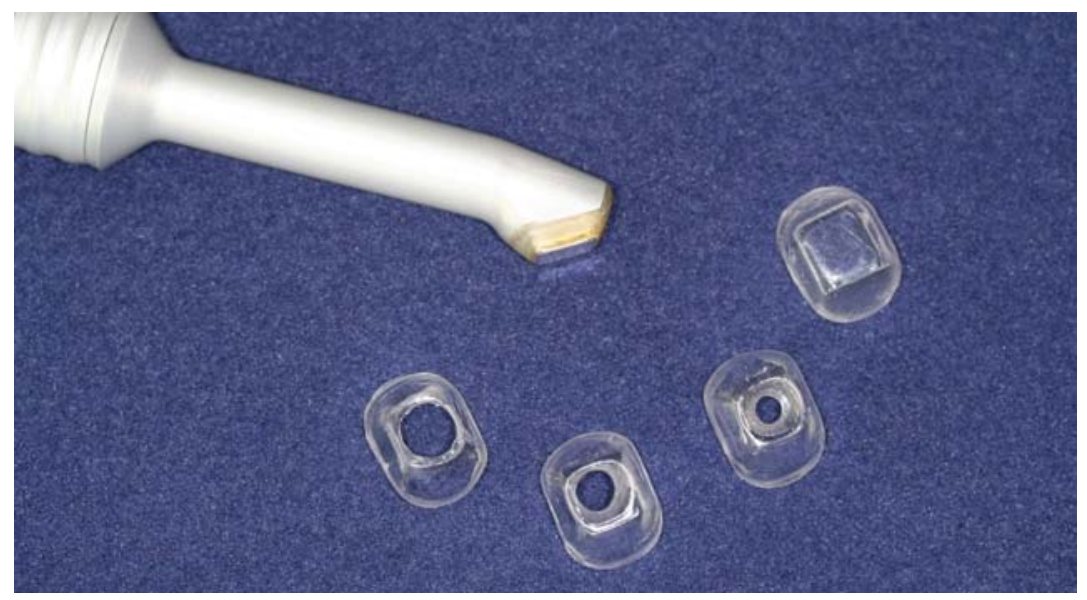

Table 3. QST parameters (in order of testing) and equipment

\begin{tabular}{lll}
\hline \multicolumn{2}{l}{ Thermal testing } & \\
CDT & Cold detection threshold & MSA Thermotest \\
WDT & Warmth detection threshold & MSA \\
TSL & Thermal sensory limen & MSA \\
PHS & $\begin{array}{l}\text { Paradoxical heat sensations on cold } \\
\text { stimulation during TSL procedure }\end{array}$ & MSA \\
CPT & Cold pain threshold & MSA \\
HPT & Heat pain threshold & MSA \\
Mechanical testing & \\
MDT & Mechanical detection threshold & Von Frey filaments \\
MPT & Mechanical pain threshold & The PinPrick \\
MPS & Mechanical pain sensitivity & The PinPrick \\
DMA & Dynamic mechanical allodynia & Cotton wisp, Q-tip, brush \\
WUR & Wind-up ratio for repetitive pinprick & The PinPrick \\
& stimulation & \\
VDT & Vibration detection threshold & Rydel-Seiffer tuning fork \\
PPT & Pressure pain threshold & Pressure algometer \\
\hline
\end{tabular}


Quantitative somatosensory testing (II)

QST was done according to a standardized comprehensive protocol (Rolke et al. 2006) with 13 parameters assessing A $\beta$-, A $\delta$-, and $\mathrm{C}$-fiber function. Table 3 presents the test parameters and the equipment. Testing was done on four sites: the skin of the right cheek, the tip of the tongue, and bilaterally on the gingival mucosa of the upper first premolar region. Each test site took 30 minutes to examine, the full examination about 2 hours. For each patient, the full QST was repeated three times. Two pre-trained, blinded examiners did the testing: on occasion 1 , examiner 1 and 2 both examined the patient (inter-examiner reliability), and after 1-3 weeks, examiner 1 repeated the procedure (intra-examiner or testretest reliability).

\section{Baseline QST (IV)}

In addition to clinical examination, full QST had been done in the pain investigations of 33 patients (List et al. 2008). At follow-up, QST was not repeated since no patients were examined clinically in the study, but baseline QST data were analyzed to examine somatosensory function as a potential outcome predictor. The QST data were collected in approximately the same fashion as in study III, but comprised only nine measures: MDT, MPT, PPT, DMAbrush and DMA-vibration (examining allodynia for vibration using an electrical toothbrush as stimulator), WUR, CDT, WDT and HPT. Sensory Z-score profiles for each patient were created. For each QST measure, a patient's result was put in relation to a reference "normal" range, determined by the test results of 35 matched controls (group mean value \pm 2 standard deviations). Each test modality was thereby defined as normal or abnormal for the patient. If two or more tests were abnormal, the patient was considered to have major sensory abnormalities. Baseline sensory function (dichotomized into major sensory abnormality profile/minor sensory abnormality profile) was examined in study IV as a potential predictor of pain resolution or pain persistence.

Baseline responsiveness to anesthesia (IV)

A subgroup of 28 patients had also participated in a nested randomized controlled trial at baseline, examining the effect of 
local anesthesia on ongoing pain (List et al. 2006). In a doubleblind, crossover design, the pain-relieving effect of lidocaine injection was compared to physiological saline injections. Patients were rated as responders-defined as reporting at least $50 \%$ pain relief on a 0-10 NRS 30 minutes after injection-or nonresponders. Baseline responsiveness to local anesthesia was examined in study IV as a potential predictor of pain resolution or persistence.

\section{Radiographic examination (III)}

The radiographic examination of the pain area included conventional radiographs (intraoral periapical radiographs and a panoramic radiograph) and a CBCT examination. The main outcome measure was periapical bone destruction. Other findings in the pain region that may be indicative of either an inflammatory pain cause or a residual surgical defect (such as excess root filling material, buccal bone loss, marginal bone defects, unfilled canals in root-filled teeth) were also recorded using a protocol. Two independent, blinded observers assessed all images, and inter- and intra-observer agreement was calculated. To reflect the clinical situation where it is common that the radiographic examination is initially limited to intraoral periapical images and possibly a panorama, later to be supplemented with a CBCT, we assessed images accordingly: conventional images only were assessed first, and then conventional images were assessed together with CBCT images.

\section{Self-report measures (III and IV)}

Study III

All patients completed a questionnaire including self-report measures on pain characteristics such as average pain intensity, pain duration, and frequency of pain.

\section{Study IV}

Self-report measures constituted the main bulk of data. The main outcome measure was global improvement measured by the Patients' Global Impression of Change (PGIC) score. According to this instrument, patients rate their overall status on a 7-point scale, 
thereby taking into consideration the pain itself and all that it entails, as very much improved, much improved, minimally improved, unchanged, minimally worse, much worse, or very much worse. As a cut-off point for defining whether the patient had improved substantially or not, the first two options - very much or much improved-were considered clinically relevant improvement.

All patients had answered a comprehensive questionnaire in 2002 when they participated in a previous study examining clinical findings and psychosocial factors in patients with $\mathrm{AO}$ (List et al. 2007). The same questionnaire was then distributed by mail in 2009 , and for those patients who chose to participate, data were available for 2002 and 2009. Reminders were also mailed, and all non-responders were then contacted per telephone and asked to participate in a short telephone interview including a subset of the questionnaire items. The questionnaire included a variety of validated instruments and questions designed to assess various aspects of pain and its consequences:

- Pain intensity. Three measures were applied: average pain; maximum pain; and Characteristic Pain Intensity (CPI, 0$100)$, a compound measure calculated by taking the mean of current pain, average pain and worst pain in the last 6 months (all on a 0-10 NRS) and multiplying it by a factor of 10 (Dworkin and LeResche 1992; Ohrbach et al. 2010).

- Pain frequency. Patients reported continuous, recurrent, occasional or no pain (Dworkin and LeResche 1992).

- Pain quality. A Swedish short form of the McGill Pain Questionnaire (SF-MPQ) with 15 descriptors of pain quality (11 sensory and 4 affective), each item scored on a 0-3-point scale $(0=$ none, $1=$ mild, $2=$ moderate, $3=$ severe) (Burckhardt and Bjelle 1994; Melzack 1987)

- Widespread pain. An anatomical drawing was used to assess bodily pain. The patient marks all areas (a maximum of ten) where pain is experienced: head, face, mouth (intraoral), throat, neck/shoulder, back, chest, abdomen, upper extremities and lower extremities. 
- Disability from pain. Graded Chronic Pain Severity (GCPS) classifies pain and its impact as grades 0-IV (grade 0: no disability, grade I-II: low disability, grade III-IV: high disability) (Dworkin and LeResche 1992)

- Psychological status. Scores for depression (20 items) and nonspecific physical symptoms (12 items) according to the SCL90R of the RDC/TMD are used to group patients as having normal status or as having moderate or severe depressive symptoms and concomitant non-specific physical symptoms (Dworkin and LeResche 1992; Ohrbach et al. 2010).

- Quality of life. The generic health-related quality of life measure Short Form 36-item Health Survey (SF-36) produces scores for eight domains: physical functioning, role-physical functioning, bodily pain, general health, vitality, social functioning, role-emotional functioning and mental health (Ware and Sherbourne 1992).

- Jaw function. The 0-10-point Jaw Functional Limitation Scale (JFLS) currently includes 20 items evaluating jaw function in the domains opening, chewing, and verbal and emotional communication. A modified version with 14 of the 20 items was used (Ohrbach et al. 2008).

Data gathered from these measures in 2002 and 2009 were compared to study the prognosis of AO. Baseline data were also examined in relation to PGIC outcome to determine if there were factors by which pain persistence or pain resolution over time could be predicted. Besides these measures, we collected patients' responses to the following questions:

- At present, do you have any ongoing pain treatment, and if so, what type of treatment (followed by a list of pharmacological and non-pharmacological options)?

- If any, how many dental treatments have been performed in the painful region during the last seven years?

- If any, what type of dental treatment has been done (e.g., dental filling, root canal treatment, tooth extraction, surgical treatment; describe the best you can)? 
- Have you received any monetary compensation for costs brought on by the pain problem, for example, from social insurance (Försäkringskassan, Sweden) or a private medical insurance?

- Do you consider that you have received a satisfactory explanation for your pain problem?

The responses to these questions were also analyzed in relation to outcome.

\section{Statistical analyses (I-IV)}

Statistical tests were performed two-tailed and at the 5\% significance level. All calculations were made using either the Statistical Package for the Social Sciences (SPSS, Ver 16.0 for Windows; SPSS Inc., Chicago, IL, USA) (II and III) or the Predictive Analytics Software (PASW) Statistics (Ver 18.0 for Windows; SPSS Inc., Chicago, IL USA) (I and IV).

Descriptive statistics with mean values and standard deviations were used to present values for continuous variables (I-IV).

One-way ANOVA for repeated measures examined differences in thresholds between (i) examination sites, (ii) examination sessions and (iii) thermode contact area sizes (I and II).

Two-way ANOVA for repeated measures analyzed gender differences in thresholds (dependent on site, session, and thermal stimulation area size) (I).

Two-way ANOVA for independent measures analyzed age and gender differences in sensory thresholds using age group and gender, respectively, as the grouping factor (II).

Paired samples t-tests with Bonferroni correction for multiple comparisons compared absolute thresholds between (i) sites, (ii) examination sessions, (iii) thermode contact area sizes, and (iv) contralateral sides (I and II). Paired samples $t$-test without Bonferroni correction compared baseline and follow-up data for continuous variables (IV). 
If differences were found with the two-way ANOVA, independent samples $\mathrm{t}$-tests were used to compare age distribution between genders (I) and sensory thresholds between age groups and between genders (II).

McNemar's chi-square test for paired samples and Wilcoxon's signed-rank test compared categorical variables in the following analyses: (i) side differences in QST measures (II), (ii) differences between baseline and follow-up data (IV), (iii) dichotomized baseline data in relation to PGIC outcome (IV), and (iv) PGIC outcome in relation to other possible outcome measures (IV).

Spearman's rank correlation coefficient ( $\rho)$ examined the correlation between (i) various outcome measures, and (ii) ongoing treatment and PGIC outcome (IV).

Kappa statistics evaluated agreement between observers assessing radiographs (III), and assessed test-retest and interexaminer agreement for categorical variables among the QST measures (II).

ICC assessed test-retest and inter-examiner agreement for continuous variables among the QST measures. As a supplement to calculating ICC in the reliability analysis, the mean intra-individual variation between assessments was analyzed to evaluate whether the observed differences between recordings was clinically relevant (II).

Backward stepwise binary logistic regression examined the likelihood of PGIC improvement in relation to each baseline variable separately. All variables were non-dichotomized when analyzed (IV).

Intra-individual variance in sensitivity (group mean values and range of threshold differences) on the maxillary and mandibular gingivae was calculated for all thermal thresholds (I).

Bland-Altman plots were drawn to analyze the occurrence of "first-examiner effect" by plotting the difference between the examiners' observations against the group mean and studying the two groups separately. Plots were drawn for all variables and at all sites (II). 
Scatter-dot graphs were drawn to examine spatial summation patterns on the tip of the tongue. In addition, equations in the form of $y=m x+b$ were calculated to determine $m$ (the slope)-the magnitude of spatial summation-for each thermal stimuli (I).

\section{Informed consent and ethical approval (I-IV)}

All four studies were performed in agreement with the 1964 Declaration of Helsinki. The Regional Ethics Review Board at Lund University approved the studies (Dnr [daybook no.] 168/2006, 51/2007 and 2009/530), and all participants signed an informed-consent form. Participants received no monetary compensation. 


\section{RESULTS}

\section{Characteristics of intraoral thermal thresholds (I)}

Site-dependent threshold differences

There were significant differences in CDTs between sites (ANOVA, $\left.\mathrm{F}_{(5,145)}=32.564 ; P<0.001\right)$. Intraorally, lowest CDTs occurred at the tongue; significantly lower than at all other intraoral test sites $(P<0.01)$. No other between-site differences in CDT were statistically significant. The mean intra-individual difference in $\mathrm{CDT}$ between the mandibular and maxillary gingiva was $3.8^{\circ} \mathrm{C}$ (SD $3.3^{\circ} \mathrm{C}$, range $10.3^{\circ} \mathrm{C}$.

Extraorally, significantly lower CDT values occurred at the infraorbital skin than at the thenar site $(P<0.01)$. The thenar threshold differed significantly from the lower lip $(P<0.01)$, mandibular gingiva $(P=0.03)$, and tongue thresholds $(P<0.01)$; whereas the infraorbital skin site differed from all intraoral sites (tongue: $P=0.045$; all others: $P<0.01$ ).

WDTs differed significantly between sites (ANOVA, $\mathrm{F}_{(5,145)}=$ 40.914; $P<0.001)$. Intraorally, WDTs were significantly lower at the tongue than at all other sites (all $P<0.01$ ) whereas all other between-site differences were nonsignificant. The mean intraindividual difference in WDT between the mandibular and maxillary gingiva was $1.9^{\circ} \mathrm{C}\left(\mathrm{SD} 1.8^{\circ} \mathrm{C}\right.$, range $\left.8.2^{\circ} \mathrm{C}\right)$.

No significant difference in WDT was found between the infraorbital and the thenar sites after Bonferroni correction. The thenar threshold differed significantly from thresholds on the 
tongue and maxillary/mandibular gingiva, and infraorbital skin differed from all intraoral sites (all $P<0.01$ ).

HPT between-site differences were also seen (ANOVA, $\mathrm{F}_{(5,145)}=$ $14.634 ; P<0.001)$. HPT was significantly lower at the tongue than at the lip $(P<0.01)$; no other intraoral between-site differences were significant. The mean intra-individual difference between the mandibular and maxillary gingiva was $1.5^{\circ} \mathrm{C}\left(\mathrm{SD} 1.6^{\circ} \mathrm{C}\right.$, range $\left.6.8^{\circ} \mathrm{C}\right)$. The infraorbital skin site had a significantly lower threshold than the thenar $(P<0.01)$.

The thenar threshold differed significantly from all intraoral sites (lower lip: $P=0.03$; all others: $P<0.01$ ), whereas the infraorbital skin threshold only differed from the lower lip $(P=0.045)$.

\section{Spatial summation of thermal stimuli}

WDT and HPT decreased with increasing size of stimulation area while in general, stimulation area size had little effect on CDT. The magnitude of spatial summation was somewhat larger for WDT (a $0.06^{\circ} \mathrm{C}$ threshold decrease for every $0.1-\mathrm{cm}^{2}$ stimulation area size increase) than for HPT (a $0.04^{\circ} \mathrm{C}$ threshold decrease for every 0.1 $\mathrm{cm}^{2}$ stimulation area size increase), and no consistent spatial summation was observed for CDT. Inter-individual variation was considerable: $\mathrm{CDT} 0.71^{\circ} \mathrm{C}\left(\mathrm{SD} 0.99^{\circ} \mathrm{C}\right)$, WDT $1.63^{\circ} \mathrm{C}\left(\mathrm{SD} 1.02^{\circ} \mathrm{C}\right)$, and HPT $1.26^{\circ} \mathrm{C}\left(\mathrm{SD} 1.42^{\circ} \mathrm{C}\right)$.

\section{Time-dependent threshold variability}

Overall, there was a tendency for thresholds to be lower in the first round of examinations and higher in subsequent examinations. The only significant difference in any of the three thermal thresholds occurred in HPT-between baseline and the 2-week examinations $(P=0.018)$. All threshold variations over time were in the range of $\pm 1^{\circ} \mathrm{C}$.

\section{Reliability of intraoral QST (II) Sensory thresholds}

CDTs $(P<0.01)$ and WDTs $(P<0.01)$ deviated significantly more from baseline temperature at the gingival sites than at the facial 
site; that is, sensitivity to these stimuli was lower on the gingiva than on facial skin. Accordingly, MDTs $(P<0.001)$ and HPTs $(P<$ $0.01)$ were significantly higher at the gingival sites than at the facial site. In contrast, PPTs $(P<0.01)$ were significantly lower on the gingiva compared to facial skin. No such difference was found for CPT, VDT, or WUR.

Of the four sites, the tongue was the most sensitive to mechanical stimulation; the tongue was significantly more sensitive than facial skin to mechanical detection $(P=0.04)$, pinprick pain $(P<0.01)$, vibration detection $(P<0.01)$, and pressure pain $(P<0.01)$ and significantly more sensitive than the gingiva to all the mechanical parameters that were included in the analysis except WUR (all $P<$ 0.01). On thermal stimulation, the tongue was more sensitive than other intraoral sites but less sensitive than facial skin. Tongue thresholds were significantly lower than gingival thresholds for CDT, WDT and HPT (all $P<0.01$ ). In contrast, tongue thresholds were significantly higher than skin thresholds for these same parameters (CDT and HPT: $P<0.01$; WDT: $P=0.015)$. CPT did not differ between test sites.

\section{Inter-examiner reliability}

Table 4 lists the ICCs for all continuous variables (CDT, WDT, TSL, CPT, HPT, MDT, MPT, MPS, WUR, VDT and PPT). PHS were a frequent finding at gingival sites; $15 / 21$ (71\%) subjects reported perceiving one or more cold stimulations as warm. Kappa values for PHS at the right and left gingival sites were 0.25 and 0.07 , respectively.

\section{Intra-examiner reliability}

Table 4 lists the ICCs for all continuous variables (CDT, WDT, TSL, CPT, HPT, MDT, MPT, MPS, WUR, VDT, and PPT). Kappa values for PHS at the left and right gingival sites were 0.34 and 0.06 , respectively.

Inter- and intra-examiner reliability analyses were supplemented with an intraindividual mean variation analysis to determine the size of the difference between observations and whether this 
difference was clinically relevant. Table 5 describes how, even though ICC was low, the difference between observations was in fact small.

Table 4. Reliability of continuous QST parameters in intraoral locations. ICC values. ICC $<0.4$ is considered poor, 0.4-0.59: fair, 0.6-0.75: good, and > 0.75: excellent agreement.

\begin{tabular}{l|ccc|ccc}
\hline & \multicolumn{3}{|c|}{ Intra-examiner } & \multicolumn{3}{c}{ Inter-examiner } \\
\hline QST & Tongue & Gingiva & Gingiva & Tongue & Gingiva & Gingiva \\
parameter & & $\mathrm{R}$ & $\mathrm{L}$ & & $\mathrm{R}$ & $\mathrm{L}$ \\
\hline CDT & 0.56 & 0.63 & 0.77 & 0.61 & 0.41 & 0.21 \\
WDT & 0.67 & 0.23 & 0.35 & 0.65 & 0.13 & 0.53 \\
TSL & 0.65 & 0.58 & 0.46 & 0.55 & 0.13 & 0.74 \\
CPT & 0.61 & 0.53 & 0.55 & 0.76 & 0.44 & 0.77 \\
HPT & 0.72 & 0.74 & 0.64 & 0.83 & 0.59 & 0.58 \\
MDT & -0.01 & 0.06 & 0.31 & 0.11 & 0.36 & 0.34 \\
MPT & 0.55 & 0.86 & 0.85 & 0.41 & 0.68 & 0.75 \\
MPS & 0.85 & 0.64 & 0.27 & 0.32 & 0.86 & 0.31 \\
WUR & 0.63 & 0.37 & -0.03 & 0.75 & 0.81 & 0.13 \\
VDT & 0.81 & 0.68 & 0.56 & 0.45 & 0.65 & 0.68 \\
PPT & 0.82 & 0.82 & 0.80 & 0.84 & 0.69 & 0.84 \\
\hline
\end{tabular}

Table 5. Mean intraindividual differences and SDs between examinations, measurements on tongue and gingiva (right side).

\begin{tabular}{l|cc|cc}
\hline QST parameter & \multicolumn{2}{|c|}{ Inter-examiner } & \multicolumn{2}{c}{ Intra-examiner } \\
\hline & Tongue & Gingiva & Tongue & Gingiva \\
$\mathrm{CDT}\left({ }^{\circ} \mathrm{C}\right)$ & $1.8(1.7)$ & $5.7(4.8)$ & $1.9(1.6)$ & $4.7(4.7)$ \\
$\mathrm{WDT}\left({ }^{\circ} \mathrm{C}\right)$ & $0.9(0.8)$ & $2.4(2.4)$ & $0.8(0.6)$ & $0.8(0.6)$ \\
$\mathrm{TSL}\left({ }^{\circ} \mathrm{C}\right)$ & $1.9(1.9)$ & $5.8(5.8)$ & $1.7(1.7)$ & $4.8(5.7)$ \\
$\mathrm{CPT}\left({ }^{\circ} \mathrm{C}\right)$ & $3.1(3.5)$ & $4.6(6.4)$ & $3.8(4.6)$ & $3.5(5.3)$ \\
$\mathrm{HPT}\left({ }^{\circ} \mathrm{C}\right)$ & $1.4(1.3)$ & $1.6(1.2)$ & $1.6(1.5)$ & $1.2(0.9)$ \\
$\operatorname{MDT}(\mathrm{mN})$ & $0.0(0.0)$ & $11.7(15.9)$ & $0.0(0.1)$ & $13.8(13.5)$ \\
$\operatorname{MPT}(\mathrm{mN})$ & $53(53)$ & $100(88)$ & $45(33)$ & $66(55)$ \\
$\operatorname{MPS}(0-100 \mathrm{NRS})$ & $0.7(1.8)$ & $0.2(0.3)$ & $0.4(0.3)$ & $0.2(0.3)$ \\
WUR $(0-100 \mathrm{NRS})$ & $0.7(0.6)$ & $1.0(0.8)$ & $0.7(0.7)$ & $1.6(2.0)$ \\
$\operatorname{VDT}(8 / 8$ scale $)$ & $0.9(0.7)$ & $1.1(0.9)$ & $0.6(0.5)$ & $1.1(0.9)$ \\
$\operatorname{PPT}(\mathrm{kPa})$ & $27(18)$ & $41(31)$ & $26(35)$ & $38(38)$ \\
\hline
\end{tabular}




\section{Additional analyses}

No age- or gender-related threshold differences were found for any parameter. Neither were any significant side-to-side differences found for any QST parameter. No systematic differences between the two examiners were found.

\section{CBCT and conventional image assessments in patients with $A O$ and SAP (III)}

In the SAP control group $(n=5)$, each patient had one tooth diagnosed with SAP. We observed periapical bone destruction in all five teeth with all methods. No additional findings were analyzed for this group.

In the AO group ( $n=20), 30$ teeth were assessed radiographically. Twenty-one of these teeth had been endodontically treated; these teeth were currently undergoing primary endodontic treatment (2 teeth), were currently undergoing retreatment (2 teeth), were rootfilled (12 teeth), or were root-filled and had undergone apical surgery ( 5 teeth). Six teeth in the pain regions had not undergone invasive treatment, and three teeth had been extracted. All patients with $\mathrm{AO}$ had at least 1 tooth in the pain region that had been endodontically treated or extracted.

Twenty-one teeth $(70 \%)$ in 12 of the patients with $\mathrm{AO}(60 \%)$ had no periapical bone destruction detectable with any method. In the other 9 teeth (8 patients), periapical bone destruction was (i) not detected on conventional images but detected with CBCT (4 teeth), (ii) suspected on conventional images but not seen in the CBCT image (1 tooth), or (iii) detected with certainty in conventional images and in the CBCT image (4 teeth). All teeth with detected or suspected periapical bone destruction, regardless of radiographic method, had been endodontically treated.

Other findings than periapical bone destruction in the AO group were more frequent when $\mathrm{CBCT}$ images were included than when conventional images were assessed alone. 
For radiographic assessments, inter-observer agreement was poor for conventional images assessed alone $(\kappa=0.19)$ and fair for conventional and СBCT images assessed together $(\kappa=0.40)$, Intraobserver agreement was good for conventional images alone $(\kappa=$ 0.65 ) and moderate for conventional and СBCT images together $(\mathrm{\kappa}$ $=0.52$ ).

\section{Prognosis and prediction of outcome in AO (IV)}

Thirty-seven patients, 31 women and 6 men, completed the study. The average age at follow-up was 62.8 years (SD 10.8 and range 38-81 years). Of the original 46 patients participating in the baseline study, only 43 were eligible in this study because three were deceased at the time for follow-up. Total response rate was $86 \% ; 32$ patients $(74 \%)$ provided full data (returning the mailed questionnaire) and a further five $(12 \%)$ provided partial data (telephone interview).

Prognosis of AO: outcome reports and changes 2002-2009 Thirteen patients of $37(35 \%)$ reported clinically relevant improvement based on PGIC ratings of 'much improved' (7 patients) or 'very much improved' (6 patients). Fifteen reported no change in overall status, and 8 perceived themselves as a little improved. Two patients reported that they were worse after the 7 years: 1 patient a little worse and 1 much worse. The global improvement rating had a fair correlation to other commonly used outcome measures. $26 / 37$ patients $(70 \% ; \rho=-0.55)$ reported a change in average pain in line with the PGIC rating (meaning that a PGIC rating of substantial improvement corresponded with an average pain decrease of $\geq 30 \%$ and a PGIC rating of less or no improvement corresponded with the absence of such a decrease in average pain). For CPI change, the corresponding figure was 29/37 $(78 \% ; \rho=-0.65)$, and for pain frequency change, $20 / 33(61 \% ; \rho=$ $0.44)$.

Average pain intensity, maximum pain intensity, CPI scores and pain frequency were all significantly lower at follow-up (all $P<$ 0.001 ). Number of painful areas (widespread pain) was unchanged over time. 
Quality of life SF-36 scores for the bodily pain $(P<0.001)$, social functioning $(P=0.013)$ and role-emotional $(P=0.001)$ domains were significantly higher at follow-up compared to baseline, indicating improved quality of life in these aspects.

Disability from pain GCPS scores decreased over time $(P<0.001)$. Thirteen patients were classified into a lower disability category (high disability/low disability/no pain) at follow-up than at baseline, 24 patients were classified in the same disability category on both occasions, and no patient was classified into a higher disability category at follow-up compared to baseline.

Jaw function was unchanged according to the JFLS total score $(P=0.689)$ on the group level.

SCL-90R depression scores showed a tendency to be higher at baseline (raw scores, $P=0.069$ ), whereas non-specific physical symptom scores did not change correspondingly $(P=0.962)$. Categorized data did not, however, show significant differences on the group level for depression or non-specific physical symptoms scores over time (for depression; $P=0.590$ and for non-specific physical symptoms; $P=1.000)$. In contrast, on the patient level, there were differences: at follow-up compared to baseline, six patients had improved and were assigned a lower depression category whereas four patients had deteriorated and were assigned a higher depression category. A similar observation was made for non-specific physical symptoms: between baseline and follow-up, five patients had improved and four patients had deteriorated.

\section{Predictors of outcome}

Among the self-reported baseline data that were analyzed for predictive value, only one factor was found to predict PGIC outcome after 7 years: low pain intensity at baseline increased the chance of an overall perception of improvement (average pain; OR 1.52 at $P=0.042$ and CPI; OR 1.56 at $P=0.041$ ). The following self-reported variables were examined: age, gender, education level, pain intensity, pain frequency, pain duration, number of pain areas (wide-spread pain), intensity scores for verbal pain descriptors, 
level of disability from pain, psychological status, and quality of life.

In 2002, patients reported having tried the following treatments (grouped after treatment type): $92 \%$ of the patients had tried pharmacological treatment (analgesics, sedatives, antidepressants, or anticonvulsants); $73 \%$ had tried surgical interventions (endodontic treatment, tooth extraction, or any form of surgical treatment in the pain area); $68 \%$, treatment aimed at stabilizing the occlusion (occlusal appliance or equilibration); $57 \%$, sensory treatment (TENS, acupuncture); 30\%, manual treatment (physiotherapy or chiropractic treatment); and 19\% had tried relaxation. Of the 29 patients who had tried analgesics at baseline, $11(38 \%)$ reported that the treatment had no effect on the pain. Corresponding figures for antidepressants were 8/11 patients $(73 \%)$ and for anticonvulsants (carbamazepine or gabapentin), $8 / 12$ patients $(67 \%)$.

Eleven of the 34 patients who reported trying pharmacological pain treatment in 2002 stated that they had experienced some pain-reducing effect. Of these, 5 also reported favorable PGIC outcomes. Positive effect of pharmacological treatment did not increase the likelihood of a favorable outcome significantly (OR $1.88 ; P=0.395)$.

The baseline clinical diagnostic test results were not predictive of long-term outcome. Data on QST profiles were available for 33 patients. In this subgroup, 11 had improved substantially according to their PGIC rating, and 22 had not. Eleven patients had QST profiles describing only minor sensory abnormality and 22 had major sensory abnormality profiles. Eight $(72 \%)$ of the patients who reported PGIC improvement had minor sensory abnormality QST profiles, whereas $14(63 \%)$ of the patients who did not report PGIC improvement had major sensory abnormality profiles. The OR for a favorable PGIC outcome with a minor abnormality QST profile was $1.11(P=0.793)$. 
Data on the responsiveness to local anesthesia in the pain area were available for 28 patients. Eight of these patients reported clinically relevant improvement in PGIC, and $4(50 \%)$ of these had experienced at least $50 \%$ pain reduction 30 minutes after lidocaine injection. Eleven $(55 \%)$ of the 20 patients who did not report improved overall pain status also not experience at least $50 \%$ pain reduction after injection. The OR for a favorable PGIC outcome was $1.22(P=0.811)$ if pain relief on lidocaine was reported.

\section{Descriptive follow-up data}

All patients responded to the question of whether they were currently under any form of pain treatment, and 26 (70\%) answered yes.

Thirteen patients reported taking benzodiazepines, 9 took analgesics, 6 took antidepressants, and 5 took gabapentin or pregabalin (no patient was taking carbamazepine). Acupuncture treatment was reported by 2 patients and TENS by 1 patient. Six patients reported physiotherapy as ongoing treatment, 4 patients relaxation, and 2 patients chiropractic treatment. Fourteen patients used occlusal appliances. Among the 13 patients reporting overall improvement (favorable PGIC), $6 \quad(46 \%)$ reported ongoing treatment. Of the 24 patients who had not improved significantly over the study period, 20 (83\%) reported ongoing treatment.

Sixteen patients reported that they were currently on pharmacological treatment (of some form), whereas 18 were on nonpharmacological treatment. Correlation analyses of PGIC with ongoing treatment type revealed that favorable PGIC was correlated with non-pharmacological treatment $(\rho=-0.438 ; P=$ $0.008)$ and pharmacological treatment $(\rho=-0.252 ; P=0.138)$.

Some patients reported new dental treatments in the pain area, although the response rate for this question (see number of responding patients for each item within parentheses). Eight patients (25) reported having received crowns or fillings, four (14) had had endodontic treatment, and two (14) tooth extractions. No 
patient reported having endodontic surgical treatment in the pain area (13).

Twenty-six of 29 patients (90\%) reported having had no economic compensation for costs brought on by the pain problem; 8 of these had a favorable PGIC and 14 had not.

Twenty of 37 patients $(54 \%)$ reported not having received a satisfactory explanation for the pain. Seven of the 13 patients $(54 \%)$ who had improved and 14 of the 24 patients $(58 \%)$ who had not improved were satisfied with the explanation given. 


\section{DISCUSSION}

The first overall aim of this thesis was to develop and assess methods that could improve differential diagnosis of intraoral pain. The issue has high clinical relevance, because an accurate diagnosis is the first step toward adequate treatment. The main findings in studies I and II were that (i) QST is feasible and reliable to use intraorally and (ii) because of considerable site-dependent variation in thresholds, normative values need to be determined for the various intraoral regions so that the individual's test results can be compared to the reference values of a site with similar sensory properties. Study III found that CBCT helps differentiate between inflammatory tooth pain and tooth pain of neuropathic character in that CBCT information on periapical appearance and 3D conditions is better than conventional radiographic information.

The second aim, prognosis assessment and prediction, was equally relevant from a patient perspective: what development can be expected after receiving the diagnosis? Can we predict whether the patient's situation will improve over time, or remain unchangedand if so, which factors are associated with a favorable or unfavorable prognosis? Study IV found that many patients with $\mathrm{AO}$ improve over time but very few experience complete remission over a 7-year period, and that low initial pain intensity increases the likelihood of a favorable outcome. 


\section{Somatosensory threshold assessment}

A main objective of studies I and II was to examine some basic properties of orofacial-in particular intraoral-somatosensory thresholds and to investigate the clinical feasibility of QST. Various procedures have been used to assess sensory nerve function: different types of stimuli and instruments, different techniques for testing, and varying principles for response assessment and interpretation. Even when similar stimuli are used, lack of standardization in assessment techniques makes it difficult to compare studies. In the last decade, QST has gained increasing interest among the pain community, and considerable progress has been made in standardizing the battery of test stimuli as well as the test methods.

The standardized, comprehensive QST protocol presented by the German Research Network on Neuropathic Pain (DFNS) in 2006 (Rolke et al. 2006a; Rolke et al. 2006b) has won acceptance. Since the introduction of the protocol, efforts have been made to collect data on healthy subjects, defining reference data stratified for different body sites as well as age and gender, including children and adolescents (Blankenburg et al. 2010; Magerl et al. 2010). In addition, patients with a range of neuropathic pain conditions have been tested and somatosensory profiles established (Maier et al. 2010). Apart from providing a clinical testing method that can be used irrespective of neurological syndrome and affected body area, somatosensory profiling may be useful in establishing a mechanism-based classification of pain.

To translate cutaneous testing techniques into a method that can be used for examination of intraoral sites, study II applied the DFNS QST protocol on the oral mucosa and found the testing procedure to be feasible with the original DFNS instruments; only minor changes were necessary due to the limited space available for instrument positioning within the oral cavity. Study I determined the influence of time variability, stimulation area size and location on thermal thresholds in oral and facial sites. These parameters all concern the reproducibility of measurements. 


\section{Time variability}

Study I found time variability over a 6-week period to be small, in the range of $\pm 1^{\circ} \mathrm{C}$, although possible diurnal variation or variation within the gestation cycle was not considered. One previous study, testing heat pain threshold of a long line of cutaneous sites over 4 weeks, found variations up to around 14\% (Meh and Denislic 1994). Another study used argon laser stimulation on oral mucosa and hairy skin to measure thermal thresholds and found variations over 24 hours to be less than 10\% (Svensson et al. 1991).

\section{Spatial summation}

Spatial summation is the addition phenomenon that is observed when increasing the size of the thermally stimulated area (i.e., the thermode contact area) results in a lower threshold for perceiving the stimulus. This phenomenon has been found to affect thermal threshold levels on skin, but no reports on oral mucosa have been published. On cutaneous sites, spatial summation has been reported by some authors to be more pronounced for warmth than for heat pain (Marks 1971) but by others, using more sophisticated methods, to be of equal magnitude (Staud et al. 2004). Spatial summation occurrence on oral mucosa was tested in study I by varying the thermode contact area and found to be of small order in the measured interval, $0.125-0.81 \mathrm{~cm}^{2}$. The tested contact area range was by necessity small, since it is not possible to apply large thermal probes inside the mouth due to space limitations. The results indicate that in intraoral thermal testing, the size of the probe or thermode used has little influence on threshold levels, thus different varieties of thermal measurement equipment can be considered essentially equal in this aspect.

\section{Test site}

Of the parameters studied, test site had the greatest influence on thermal thresholds. Study I found substantial between-site differences in thermal thresholds for cold, warmth and heat pain; intraorally, the difference was most pronounced between the gingiva and the tongue. This indicates that if thermal threshold levels are to be used, for example, to assess sensory nerve function, reference values for normal function must be established for a 
range of intraoral sites. The observations later made in study II support these findings, as do several previous studies (Green 1984; Green and Gelhard 1987; Svensson et al. 1992)

The measuring methods applied in study I to examine properties of thermal thresholds were standardized and followed the methods described in the DFNS protocol, although all of the included thermal parameters were not used. Study I subjects were all young individuals, so the effect of age was not studied, and no sex dependent differences in threshold levels were found. Some studies reported similar results on cutaneous sites (Defrin et al. 2009), whereas others found that females have lower thermal thresholds (Meh and Denislic 1994). Study I findings on time variability and spatial summation should be considered generalizable for healthy individuals.

\section{Reliability of somatosensory testing}

The reliability of cutaneous application of the DFNS 13-measure QST protocol was reported to be good (Geber et al. 2007; Geber et al. 2011). In study II, protocol reliability for orofacial and intraoral application was generally acceptable, with better reliability for some measures than for others. For several measures, there was considerable variation in the reliability between sites.

On the gingiva, which is the site that would be most interesting to test in patients with tooth pain suspected to be of neuropathic origin, thermal pain thresholds (CPT and HPT), vibration detection threshold (VDT), and mechanical pain thresholds (MPT and PPT) had highest overall reliability. Tests designed to detect central sensitization (DMA, PHS and WUR) had the lowest reliability. The reason may be that study II used healthy pain-free subjects, but a multicenter study on patients with different neuropathic conditions with or without pain symptoms (but all with lesions or disease affecting the somatosensory system) also found low reliability for PHS and WUR on cutaneous sites (Geber et al. 2011). Preliminary results of an ongoing multicenter study on orofacial pain patients indicate that reliability patterns in patients with AO are similar to in pain-free subjects. 
Other findings of the reliability study (II) that are of interest for future applications is that age and gender did not seem to affect intraoral threshold levels significantly, although the study was not powered to detect such differences. Older subjects are generally reported to have higher thresholds for somatosensory stimuli, but the decline in function is reported to be dependent on the length of the afferent pathway, with greater age-related decline of function in distal extremities (Lautenbacher and Strian 1991; Rolke et al. 2006a). Consequently, least change should be expected where the pathway is short, as in the trigeminal area. Other studies reported gender differences in sensitivity to several stimuli, noxious in particular, and found women to have lower thresholds (Chesterton et al. 2003; Riley et al. 1998; Rolke et al. 2006a). To determine the range of normal interindividual variation in intraoral sensory function, a considerably larger material than in study II is needed and is currently being collected.

On the individual level, study II found side differences in threshold level between the right and left side gingival sites. On the group level, no systematic, between-side differences occurred. This finding may indicate that side-to-side variation of perception and pain sensitivity within an individual is normal. Because side comparison (the pain site and the corresponding site on the painfree side) is often used to determine whether sensory function is abnormal, the issue needs to be further explored. For example, the prevalence of intraoral side differences could be assessed and the normal range of such differences calculated to determine whether the finding has clinical importance.

Overall, studies I and II provided new knowledge needed to design and validate tests methods for detecting somatosensory changes intraorally.

\section{Radiographic examination in atypical odontalgia}

Study III examined the supplemental diagnostic value of CBCT in intraoral pain investigation. The main question was whether CBCT added valuable diagnostic information when $\mathrm{AO}$ was suspected to be the cause of pain. For a diagnostic test to be employed, its use 
should be beneficial to the patient. Such benefits may be an impact on diagnostic thinking, therapeutic choice or patient outcome. To provide the best available treatment without delay, misdiagnosis should be avoided. In patients with $\mathrm{AO}$, we know that pain symptoms are often misinterpreted as being of endodontic origin, and that the patient is consequently treated for endodontic disease. Therefore, ruling out endodontic disease with as high certainty as possible is likely beneficial to the patient. Conversely, if the pain cause is indeed endodontic, it is essential to find the offending tooth so that adequate endodontic treatment can be initiated without delay.

Study III examined a group of patients in which we were reasonably sure that the pain cause was not endodontic disease. Periapical bone destruction was sometimes present but was interpreted as being caused by, for example, recent surgical intervention. In the majority of cases, where the CBCT examination failed to detect signs of bone destruction and thereby confirmed the likewise negative findings of the intraoral radiographs, the added input had influence on the diagnostic thinking. Since the sensitivity of CBCT examination is reported to be higher than for conventional radiographic examination, the risk of a false negative result (the risk of being wrong when declaring the patient free of periapical disease) was lower. Periapical disease was thus excluded with greater certainty than before the CBCT, and confidence in the tentative diagnosis of $\mathrm{AO}$ was higher.

In the opposite scenario, when bone defects were already visible on panoramic and periapical radiographs, a confirming CBCT examination added no valuable diagnostic information - the reason for the pain was still unclear. Still, other findings in the pain area that are interpreted differently due to the $3 \mathrm{D}$ assessment in CBCT could conceivably have an impact on diagnostic outcome and therapeutic choice, although no such findings were made in study III. A bone defect, seemingly located around the root apex on intraoral images but located in another plane on CBCT (e.g., the buccal bone plate) and with bone tissue surrounding the apices, is one example. Additional roots, untreated root canals, and the 
presence of periapical bone destruction in an upper molar may be difficult to assess in intraoral images. One study observed 31\% more periapical bone destructions and $10 \%$ more root canals on CBCT images than on periapical radiographs (Lofthag-Hansen et al. 2007).

Observer agreement of image assessment ranged from poor to good. While intra-observer agreement was moderate to good, interobserver agreement on conventional image assessment (periapical and panoramic images) was poor, $\mathrm{\kappa}=0.19$. One contributing reason for this low agreement may be that the observers knew the patients were under pain investigation. Frequent signs of a clinical problem (e.g., root-filled teeth, teeth showing signs of presently undergoing endodontic retreatment, evidence of root canal dressings, signs of previous apicectomies, presence of temporary fillings) may have made image interpretation more complex. Other studies have reported similar (Sogur et al. 2009) or greater (Estrela et al. 2008; Patel et al. 2009) agreement for detecting periapical bone destruction, but in these studies, image assessment was made on different materials, such as mechanically or chemically (in vitro) induced bone destruction. The total agreement between assessments ranged from $57 \%$ to $83 \%$ in our material, which is considered reasonably high. All image interpretations discussed here are the results of consensus assessment conducted when observers disagreed.

When a new diagnostic method is introduced, its scientific properties need to be evaluated. High sensitivity and improved accuracy do not always go hand in hand; low specificity may be a risk. The greater ability of CBCT to visualize periapical bone destruction deserves careful consideration. In periapical radiographs of human maxillary incisors, evidence of bone destruction was strongly correlated to histological findings of inflammatory infiltrates in an autopsy material (Brynolf 1967). In CBCT images, no corresponding correlation has yet been established in humans. Thus, we do not know how well periapical bone destructions seen in CBCT images correspond with inflammation 
of the periapical tissues; in other words, the validity of CBCT to detect periapical disease is still unknown.

Today, there is an ongoing discussion in endodontics on how to interpret small periapical bone destructions around the apices of root-filled teeth. Should the presence of such signs be interpreted unconditionally as disease? To what extent should such findings guide treatment decision? The magnitude of this problem would likely increase if CBCT was the method of choice for periapical assessment. When pain and other symptoms are absent, clinicians are usually inclined to be conservative and to postpone decisions of further irreversible treatment until a diagnosis of periapical disease is less uncertain. If the patient presents with the same radiographic appearance, and also reports continuous or recurrent pain of moderate to severe intensity, the treatment decision is not unlikely to be more radical.

In patients with $\mathrm{AO}$, repeated invasive treatment has been reported not only to be unsuccessful in relieving the pain but also to increase pain intensity, to increase pain frequency, and to cause the pain to spread over a wider area (Mock et al. 1985; Schnurr and Brooke 1992; Woda and Pionchon 1999). The phenomenon is anecdotally reported in literature as a clinical observation and has not been extensively investigated. The effect is considered the consequence of applying further strain to an already dysfunctional nervous system, and invasive treatment is contraindicated and should thus be avoided as far as possible. In this patient group, it would therefore seem that we should be even more conservative in demanding good evidence of disease before any invasive treatment is initiated, and interpret positive CBCT findings with ultimate caution.

\section{Prognosis assessment}

Study IV examined the long-term prognosis of AO. The main finding was that about one-third of the patients in the study perceived themselves considerably improved over time. Most other reports of long-term development of chronic pain conditions are treatment studies, and reports of natural progression are scarce. 
Study IV patients did not undergo any standard treatment regime, partly because they were collected from orofacial pain clinics in four geographic regions in Sweden, with varying clinical routines and available therapeutic options, and partly because no such recommended standard treatment really exists. Patients' preferences of therapy were accommodated and choice and duration of treatment dictated by clinical requirements rather than more rigid treatment schedules. We thus used a naturalistic study approach, which has been recommended as an option for gaining information on prognosis and treatment effect when randomized controlled trials are difficult to conduct, for example, when studying rare conditions (Leichsenring 2004).

A study by one research group followed patients with post-herpetic neuralgia for up to 11 years and found that $47 \%$ were doing well (34\% good and $13 \%$ excellent) at their final assessment, and half were medication free. The remaining 53\% were doing poorly, defined as 'presence of moderate pain for at least part of the day and/or interference with activities of daily living, side effects and/or lack of satisfaction with pain control' (Watson et al. 1991). Although the outcome measures were not identical, the study compares well with our results; while $35 \%$ of our patients were substantially improved, around half reported no change or an overall worse situation after the 7 years.

For comparison with non-neuropathic pain conditions, a longitudinal study on TMD pain-considered mainly musculoskeletal in origin-reported complete remission in $49 \%$ of cases, and another $22 \%$ were at least $20 \%$ improved; the outcome variable was average pain intensity (Ohrbach and Dworkin 1998). The difference in outcome may indicate that there are important differences between $\mathrm{AO}$ and TMD pain, for example, in mechanisms for pain maintenance.

Considerable costs are associated with chronic pain: (i) on the patient's part, disability, suffering and psychosocial consequences as well as functional, esthetic and financial losses; (ii) on the dentist's part, frustration and despair (sometimes leading to a 
breakdown in communication with the patient) as well as financial issues associated with unsuccessful treatment; and (iii) on society's part, repeated care-seeking on different levels (e.g., general dentists, dental specialists, physicians, medical specialists, psychologists, physiotherapists) and indirect costs generated by the patient's reduced capacity to work due to chronic pain, in many cases for years. Because chronic pain is multidimensional, prognosis assessment should include numerous aspects, not forgetting assessment of economical components and patient-dentist communication issues. Study IV used self-report data only, so these last two aspects were possible only in a limited way. Even so, a vast majority of patients reported lack of economic compensation for pain-related costs and more than half of the patients considered the offered pain explanations unsatisfactory. These findings have generated ideas for future studies.

The main outcome measure in study IV was global improvement, as assessed by the Patients' Global Impression of Change scale, PGIC. Global ratings of change reflect patient satisfaction with the overall situation and may be a more relevant measure than those that assess only one of a few aspects of the complex pain experience, for example, change in average pain intensity or change in pain frequency (Collins et al. 2001). IMMPACT has recommended PGIC as a core outcome measure in chronic pain trials (Dworkin et al. 2005; Haythornthwaite 2010), and it has been widely used in studies of various conditions (Dworkin et al. 2005). Whereas most treatment studies that use PGIC as an outcome measure are relatively short in duration, 3-6 months, in study IV we asked patients to rate their perceived change in pain experience over a much longer period, 7 years. Memory bias may affect the accuracy of this rating, because it is likely difficult for the patient to remember details over such a long time (Stone et al. 2005). So, PGIC ratings were compared to the 2002-2009 changes in pain intensity and pain frequency, and found to have reasonable agreement $(61-78 \%)$, which indicates that the reported PGIC improvement is robust. One study previously reported a consistent relationship between the PGIC ratings 'very much improved' or 'much improved' and a 30\% reduction in pain intensity, and found 
it to be stable across chronic pain conditions, age and gender (Farrar et al. 2001). The researchers also found that these cut-off values correlated well with the clinician's perception of clinically important improvement. The scales and cut-off points in study IV and in the Farrar study were identical.

\section{Pain and disability change over time}

Chronic pain affects the individual on many levels. In patients with AO, little was known of how the situation changes over time. To investigate this, parameters measuring various aspects of pain, physical functioning and emotional functioning were compared over the 7-year study period. The results showed that on the group level, pain had decreased significantly in both intensity and frequency. Physical functioning, represented by GCPS scores, had also improved. Quality of life in general, represented by SF-36 scores, was unaffected except in the bodily pain, social functioning and role-emotional domains, where function was significantly improved. Jaw function was unchanged over time. Physical functioning and social functioning are often reported to be closely associated with pain.

Emotional functioning, represented by SCL-90R depression and non-physical symptoms scores, was unchanged. On the individual level, some patients had improved and others had deteriorated.

\section{Outcome prediction}

In patients with $\mathrm{AO}$, mechanisms for pain maintenance are not well established. Studying development over time and relating outcome to clinical and psychosocial background variables may improve our understanding. Clinically, being able to predict longterm outcome in pain patients with chronic disorders would be valuable, as would knowing which subgroup of patients will most likely respond to a certain treatment.

Study IV examined self-report data and clinical measures for their predictive value for pain decrease. The material, although substantial for the AO condition, was still not large enough to allow a logistic regression analysis with multiple covariates 
simultaneously. Instead, (i) the baseline values of each parameter were dichotomized and related to a dichotomized PGIC-clinically relevant improvement or not-and (ii) a logistic regression analysis was performed with each covariate studied separately. These methods identified only one factor as predictive of a favorable outcome: low baseline pain intensity. Other background factors failed to reach statistical significance when analyzed as possible predictors, but some appeared to promote favorable outcome: male gender, low worst pain intensity, and low grade of disability from pain at baseline. Interactions between factors were not possible to investigate, so the results must be interpreted with caution.

The clinical diagnostic tests-QST and lidocaine injection in the pain area-were also analyzed for prognostic value.

Abnormal sensory perception of non-noxious and noxious stimuli is considered an important sign of neuropathy, and in the clinical diagnosis of neuropathic pain, such changes in somatosensory function are therefore routinely assessed. However, transient changes in sensory function also occur in pain conditions of inflammatory and functional origin (Latremoliere and Woolf 2009; Maixner et al. 1995). At baseline, most patients with AO in study IV, 94\%, had at least one somatosensory abnormality and $67 \%$ had two or more. The presence of a high degree of somatosensory abnormalities did not consistently predict an unfavorable outcome. The prevalence of sensory abnormalities in our material compares well to a recent large study which found that $92 \%$ of patients with various neuropathic pain conditions had at least one abnormality (Maier et al. 2010). Further studies are still needed to more precisely determine the range of normality for intraoral sensory thresholds, and also to examine to what degree somatosensory abnormalities inside the mouth are representative of neuropathic pain conditions. Z-score sensory profiling of patients suffering from pain conditions of various origins may improve differential diagnostic certainty, and not least provide valuable information on pain mechanisms. 
Lidocaine responsiveness was investigated in the baseline study by List and co-workers (List et al. 2006). They found that local anesthesia produced $50 \%$ or more pain reduction in only $54 \%$ of the patients. The hypothesized explanation was that in a considerable number of patients with $\mathrm{AO}$, central sensitization may be responsible for the pain, and thus the pain would not be much affected by peripheral anesthesia. It has been suggested that central sensitization plays a major role in pain maintenance in chronic conditions (Woolf 2011), and that pain with predominantly central pain mechanisms is more difficult to successfully treat. Study IV did not find evidence that patients who responded well to lidocaine injection at baseline had a better long-term prognosis, but it is also possible that the material was insufficient in size to reveal such a correlation. 


\section{CONCLUSIONS,}

\section{CLINICAL IMPLICATIONS, AND FUTURE WORK PLAN}

- Intraoral thermal thresholds are affected by site location. Spatial summation on the tongue is small for WDT and HPT and inconclusive for CDT with thermode contact areas of 0.81 $\mathrm{cm}^{2}$ and smaller. Threshold variability over a 6 -week period is modest (I).

- The reliability of orofacial QST in subjects with no orofacial pain complaint is adequate for future application of the method (II).

- The diagnostic yield is higher when the conventional radiographic examination is supplemented with $\mathrm{CBCT}$ in the investigation of patients with suspected AO. The additional findings made with CBCT are such that they may be relevant in the diagnosis of persistent intraoral pain conditions (III).

- Many patients with AO experience an improvement in overall status over time. Low initial pain intensity may predict a favorable prognosis (IV).

The first two studies of this thesis added new and valuable knowledge on somatosensory testing in the orofacial area, but many pieces are still missing, and more studies are needed before the method can be used in clinical pain investigations and we can be certain about what the results actually mean. For example, if thermal thresholds are to be used to disclose sensory changes intra- 
and extraorally, reference QST values should be determined for different sites. Testing the reliability of QST in patients with orofacial pain is another issue that is currently being addressed by our group in an ongoing multicenter study.

Moreover, as one study points out (Hansson et al. 2007), there are limitations to QST and to somatosensory assessment in general as a diagnostic method for neuropathic pain, since changes in sensory function occur with the physiologic changes in the nervous system that take place in many pain conditions and not just in neuropathic pain (Kosek and Ordeberg 2000; Leffler et al. 2003). Khan et al. observed reduced mechanical pain thresholds (on biting teeth together) in teeth with irreversible pulpitis and symptomatic apical periodontitis and also in contralateral teeth, suggesting involvement of central mechanisms for acute tooth pain (Khan et al. 2007). For this reason, studies evaluating similarities and differences between odontogenic and non-odontogenic tooth pain in this respect, describing sensory profiles of various pain disorders, are already in progress as a step towards validity assessment of QST.

Also, to be helpful to the dentists who see these patients, we need to develop clinically feasible methods that are less of a laboratory test and more of a screening test. Pain that is highly likely to be neuropathic in origin needs to be identified more easily. The qualitative somatosensory examination-often referred to as a 'bedside' or 'chairside' examination-needs to be validated and correlated to QST findings. It may also be possible to identify a shortlist of QST measures that are particularly useful for differential diagnosis.

The third study in the thesis explored CBCT as a supplementary radiographic examination method when $\mathrm{AO}$ is suspected. The results indicate that the method should be included in the diagnostic work-up for selected patients, more specifically to exclude periapical disease. But since we do not know how to adequately interpret small bone destructions around the apices of root-filled teeth, it is possible that other imaging methods than 
radiography are superior in detecting disease. Magnetic resonance imaging (MRI) has the ability to detect bone marrow edema, which may indicate presence of inflammatory infiltrates in bone tissue (Eustace et al. 2001). In apical periodontitis, inflammation is present and may thus be detected with MRI of the jaws. Study III patients were examined with MRI as the next step in the pain investigation, and preliminary results from this study show that signs of edema are present in the pain region of a number of patients diagnosed with $\mathrm{AO}$. The implications of this finding are unclear. Studying the correlation of CBCT findings to MRI findings may allow the interpretation of CBCT images to be considered in a different light.

The clinical implication of study IV is that, in general, improvement of some degree can likely be expected over time for a patient diagnosed with $\mathrm{AO}$, and especially if baseline pain level is moderate. However, the prognosis for chronic pain conditions like AO likely depends on many factors. A larger material than was available in the fourth and final study of this thesis is needed to more reliably assess predictors and risk factors for persistent pain, but such a material is of course not easily collected in this relatively rare condition. Other research methods may add important knowledge on how patients fare and how we should act as professionals to provide the best possible care. Qualitative studies looking into what characterizes patients who do improve over time compared with patients who do not improve may shed light on what will be the best therapeutic approach in AO. 


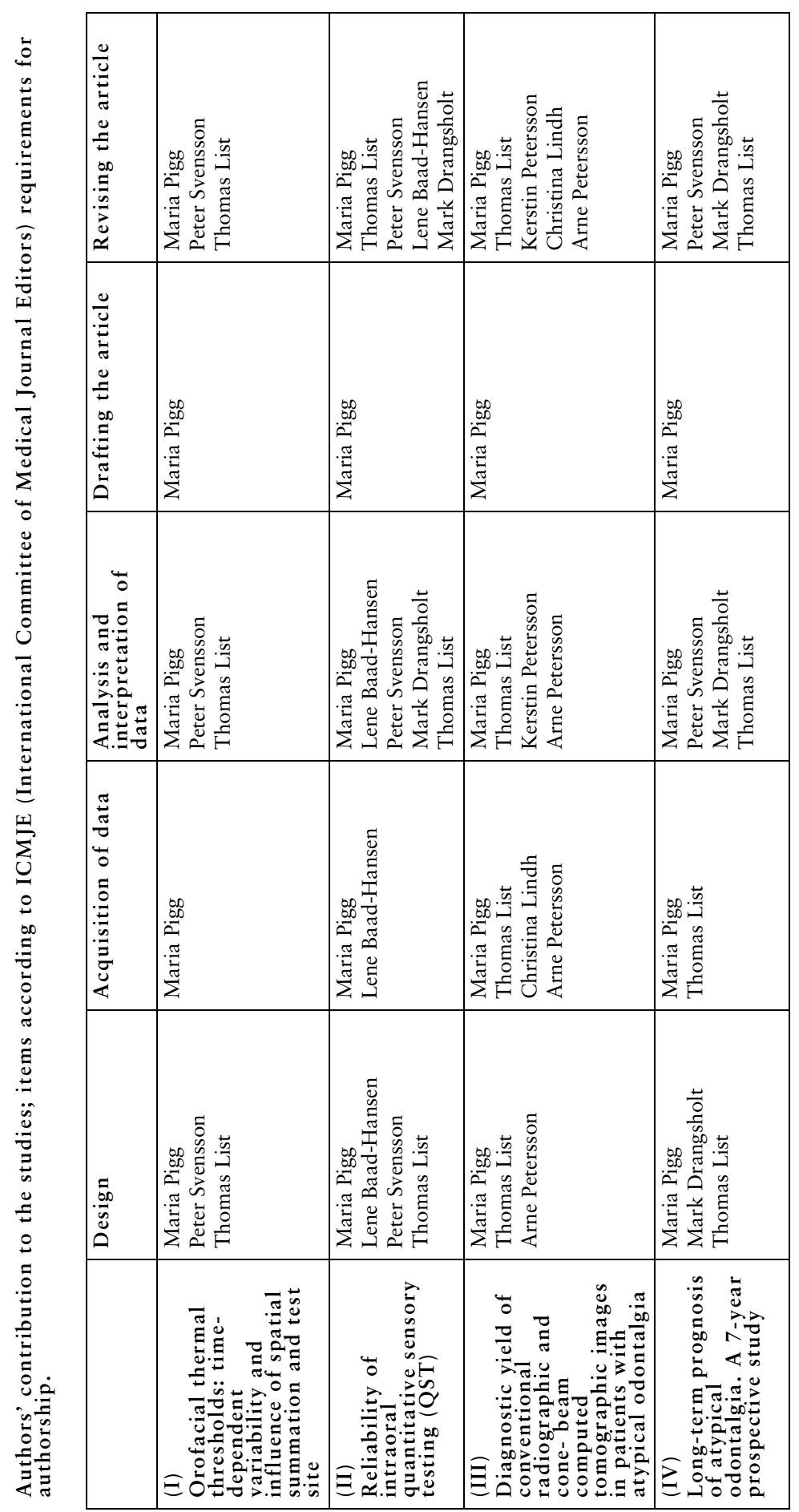




\section{ACKNOWLEDGEMENTS}

Many people have inspired my thinking, promoted my learning, and generously supported me during the work with this thesis. I wish to express my sincere gratitude to everyone for that help and for being my friends.

In particular, I want to thank:

Professor Thomas List, primary supervisor and co-author. You are wonderfully inspiring to work with; challenging my reasoning, always a step ahead, and amazingly generous in everything you do. I could not have wished for a better mentor.

Professor Kerstin Petersson, co-supervisor and co-author. You are a very much appreciated source of knowledge on science, endodontics, and everything else a girl needs to know. I am so lucky your office is just next door!

Professor Arne Petersson, supervisor and co-author. For sharing your great knowledge and enthusiasm, and for answering your phone even when you are out running in Lödde Sandskog.

Professor Peter Svensson, co-author, and near-supervisor, for knowing virtually everything about orofacial pain and being eager to share it. In Danish, too. 
My co-authors, Associate Professors Lene Baad-Hansen and Mark Drangsholt and Professor Christina Lindh, for assistance in collection and interpretation of data and for sharing your broad knowledge.

Associate Professor Eva Wolf, my boss at the Department of Endodontics, for intermittently reminding me that research is fun.

Gail Conrod-List, for first-rate linguistic revision and editing of the articles and the thesis, and above all for helping me learn scientific writing.

Per-Erik Isberg, for excellent advice on statistics and for encouragement $\&$ guidance in my stubborn wish to understand and do things myself.

Bo Johansson at Somedic, for sharing the mysteries of thermal stimulation.

The staff of the Departments of Endodontics and Stomatognathic Physiology; especially Gunilla Johnsson, Lotta Rosengren, Gunilla Millman, Yvonne Ljung Möller, Marina Braun Lindahl and Camilla Wågréus for invaluable help in managing sensory testing equipment, finding radiographs and keeping check of study participants, and Veronica Cronholm Nilsson and Elisabeth Edwinson for ready administrative support.

The guys at Repro, Peter Olsson and Roger Larsson, for printing things on huge papers in a hurry.

All my dear colleagues, past and present, at the Faculty of Odontology, for many stimulating discussions on scientific and completely unscientific topics.

The study participants, patients and healthy control subjects alike. Without your help we would understand less and wonder more. 
All my favourite people in the world with sharp brains, wild and reckless ideas, and big hearts; for inspiring me in so many ways. I know exactly who you are, and I hope you all do, too.

Sten and Monica Persson, my parents. You have always supported me and made me believe I could do anything I wanted. Because of the confidence you inspired, I am doing it.

Juhani, my husband, for your endless love and support; and Julia, Lovisa and Ellen, our lovely daughters, for being so patient and loving and for putting research in the right perspective-after horses, soccer and food on the table. You are what matters most in my life.

Research grants were received from:

- The Faculty of Odontology, Malmö University

- The Swedish Dental Society

- The South Swedish Dental Society

- TePe Munhygienprodukter AB, Malmö

- The National Institutes for Health (NIH); K12-DE14069 and R21-DE018768 (Dr Mark Drangsholt) 


\section{REFERENCES}

Allerbring M, Hägerstam G. Chronic idiopathic orofacial pain. A long-term follow-up study. Acta Odontol Scand 2004; 62:66-9.

Baad-Hansen L, List T, Jensen TS, Svensson P. Increased pain sensitivity to intraoral capsaicin in patients with atypical odontalgia. J Orofac Pain 2006a; 20:107-14.

Baad-Hansen L, List T, Kaube H, Jensen TS, Svensson P. Blink reflexes in patients with atypical odontalgia and matched healthy controls. Exp Brain Res 2006b; 172:498-506.

Baad-Hansen L, Juhl GI, Jensen TS, Brandsborg B, Svensson P. Differential effect of intravenous S-ketamine and fentanyl on atypical odontalgia and capsaicin-evoked pain. Pain 2007; 129:46-54.

Bekkering GE, Bala MM, Reid K, Kellen E, Harker J, Riemsma R, Huygen FJ, Kleijnen J. Epidemiology of chronic pain and its treatment in The Netherlands. Neth J Med 2011; 69:141-53.

Bender IB. Pulpal pain diagnosis-a review. J Endod 2000; 26:175-9.

Blankenburg M, Boekens H, Hechler T, Maier C, Krumova E, Scherens A, Magerl W, Aksu F, Zernikow B. Reference values for quantitative sensory testing in children and adolescents: developmental and gender differences of somatosensory perception. Pain 2010; 149:76-88.

Bossuyt PM, Reitsma JB, Bruns DE, Gatsonis CA, Glasziou PP, Irwig LM, Lijmer JG, Moher D, Rennie D, de Vet HC, Standards for Reporting of Diagnostic Accuracy. Towards complete and accurate reporting of studies of diagnostic accuracy: the STARD initiative. BMJ 2003; 326:41-4.

Breivik H, Collett B, Ventafridda V, Cohen R, Gallacher D. Survey of chronic pain in Europe: prevalence, impact on daily life, and treatment. Eur J Pain 2006; 10:287-333. 
Brynolf I. A histological and roentgenological study of the periapical region of human upper incisors. Odontol Revy 1967;1-167.

Burckhardt CS, Bjelle A. A Swedish version of the short-form McGill Pain Questionnaire. Scand J Rheumatol 1994; 23:77-81.

Chesterton LS, Barlas P, Foster NE, Baxter GD, Wright CC. Gender differences in pressure pain threshold in healthy humans. Pain 2003; 101:259-66.

Christiansen R, Kirkevang LL, Gotfredsen E, Wenzel A. Periapical radiography and cone beam computed tomography for assessment of the periapical bone defect 1 week and 12 months after root-end resection. Dentomaxillofac Radiol 2009; 38:531-6.

Collett B. The burden of chronic pain. Curr Med Res Opin 2011; 27:2065-6.

Collins SL, Edwards J, Moore RA, Smith LA, McQuay HJ. Seeking a simple measure of analgesia for mega-trials: is a single global assessment good enough? Pain 2001; 91:189-94.

Cruccu G, Sommer C, Anand P, Attal N, Baron R, Garcia-Larrea L, Haanpää M, Jensen TS, Serra J, Treede RD. EFNS guidelines on neuropathic pain assessment: revised 2009. Eur J Neurol 2010; 17:1010-8.

Cruccu G, Truini A. Neuropathic pain and its assessment. Surg Oncol 2010; 19:149-54.

Cruccu G, Anand P, Attal N, Garcia-Larrea L, Haanpää M, Jorum E, Serra J, Jensen TS. EFNS guidelines on neuropathic pain assessment. Eur J Neurol 2004; 11:153-62.

Defrin R, Shramm L, Eli I. Gender role expectations of pain is associated with pain tolerance limit but not with pain threshold. Pain 2009; 145:230-6.

Diatchenko L, Slade GD, Nackley AG, Bhalang K, Sigurdsson A, Belfer I, Goldman D, Xu K, Shabalina SA, Shagin D, Max MB, Makarov SS, Maixner W. Genetic basis for individual variations in pain perception and the development of a chronic pain condition. Hum Mol Genet 2005; 14:135-43.

Dworkin SF, LeResche L. Research diagnostic criteria for temporomandibular disorders: review, criteria, examinations and specifications, critique. J Craniomandib Disord 1992; 6:301-55.

Dworkin RH, Turk DC, Farrar JT, Haythornthwaite JA, Jensen MP, Katz NP, Kerns RD, Stucki G, Allen RR, Bellamy N, Carr DB, Chandler J, Cowan P, Dionne R, Galer BS, Hertz S, Jadad AR, Kramer LD, Manning DC, Martin S, McCormick CG, McDermott MP, McGrath P, Quessy S, Rappaport BA, Robbins W, Robinson JP, Rothman M, Royal MA, Simon L, Stauffer JW, Stein W, Tollett J, Wernicke J, Witter J, IMMPACT. Core outcome measures for chronic pain clinical trials: IMMPACT recommendations. Pain 2005; 113:9-19. 
Dworkin SF, Massoth DL. Temporomandibular disorders and chronic pain: disease or illness? J Prosthet Dent 1994; 72:29-38.

Estrela C, Bueno MR, Leles CR, Azevedo B, Azevedo JR. Accuracy of cone beam computed tomography and panoramic and periapical radiography for detection of apical periodontitis. J Endod 2008; 34:273-9.

Eustace S, Keogh C, Blake M, Ward RJ, Oder PD, Dimasi M. MR imaging of bone oedema: mechanisms and interpretation. Clin Radiol 2001; 56:4-12.

Farrar JT, Young JP Jr, LaMoreaux L, Werth JL, Poole RM. Clinical importance of changes in chronic pain intensity measured on an 11-point numerical pain rating scale. Pain 2001; 94:149-58.

Geber C, Klein T, Azad S, Birklein F, Gierthmuhlen J, Huge V, Lauchart M, Nitzsche D, Stengel M, Valet M, Baron R, Maier C, Tölle T, Treede RD. Test-retest and interobserver reliability of quantitative sensory testing according to the protocol of the German Research Network on Neuropathic Pain (DFNS): a multi-centre study. Pain 2011; 152:548-56.

Geber C, Klein T, Rolke R, Magerl W, Dieterich M, Birklein F, Treede RD. Test/Retest- and interobserver-reliability in Quantitative Sensory Testing according to the protocol on the German Network on Neuropathic Pain (DFNS). Eur J Pain 2007;11: 587.

Gopikrishna V, Pradeep G, Venkateshbabu N. Assessment of pulp vitality: a review. Int J Paediatr Dent 2009; 19:3-15.

Graff-Radford SB, Solberg WK. Atypical odontalgia. J Craniomandib Disord 1992; 6:260-5.

Green BG, Gelhard B. Perception of temperature on oral and facial skin. Somatosens Res 1987; 4:191-200.

Green BG. Thermal perception on lingual and labial skin. Percept Psychophys 1984; 36:209-20.

Haanpää M, Attal N, Backonja M, Baron R, Bennett M, Bouhassira D, Cruccu G, Hansson P, Haythornthwaite JA, Iannetti GD, Jensen TS, Kauppila T, Nurmikko TJ, Rice AS, Rowbotham M, Serra J, Sommer C, Smith BH, Treede RD. NeuPSIG guidelines on neuropathic pain assessment. Pain 2011; 152:14-27.

Han KR, Kim C, Chae YJ, Kim DW. Efficacy and safety of high concentration lidocaine for trigeminal nerve block in patients with trigeminal neuralgia. Int J Clin Pract 2008; 62:248-54.

Hansson P, Backonja M, Bouhassira D. Usefulness and limitations of quantitative sensory testing: clinical and research application in neuropathic pain states. Pain 2007; 129:256-9.

Hargreaves KM, Swift JQ, Roszkowski MT, Bowles W, Garry MG, Jackson DL. Pharmacology of peripheral neuropeptide and inflammatory mediator release. Oral Surg Oral Med Oral Pathol 1994; 78:503-10. 
Haythornthwaite JA. IMMPACT recommendations for clinical trials: opportunities for the RDC/TMD. J Oral Rehabil 2010; 37:799-806.

Holland GR. Periapical neural changes after pulpectomy. Oral Surg Oral Med Oral Pathol Oral Radiol Endod 1995; 80:726-34.

IASP pain taxonomy 2011; http://www.iasp-pain.org/Content/Navigation Menu/General ResourceLinks/PainDefinitions/default.htm

Juhl GI, Jensen TS, Norholt SE, Svensson P. Central sensitization phenomena after third molar surgery: a quantitative sensory testing study. Eur J Pain 2008; 12:116-27.

Khan AA, Owatz CB, Schindler WG, Schwartz SA, Keiser K, Hargreaves KM. Measurement of mechanical allodynia and local anesthetic efficacy in patients with irreversible pulpitis and acute periradicular periodontitis. J Endod 2007; 33:796-9.

Kosek E, Ordeberg G. Abnormalities of somatosensory perception in patients with painful osteoarthritis normalize following successful treatment. Eur J Pain 2000; 4:229-38.

Lang E, Kaltenhauser M, Seidler S, Mattenklodt P, Neundorfer B. Persistent idiopathic facial pain exists independent of somatosensory input from the painful region: findings from quantitative sensory functions and somatotopy of the primary somatosensory cortex. Pain 2005; 118:80-91.

Latremoliere A, Woolf CJ. Central sensitization: a generator of pain hypersensitivity by central neural plasticity. J Pain 2009; 10:895-926.

Lautenbacher S, Strian F. Similarities in age differences in heat pain perception and thermal sensitivity. Funct Neurol 1991; 6:129-35.

Leffler AS, Hansson P, Kosek E. Somatosensory perception in patients suffering from long-term trapezius myalgia at the site overlying the most painful part of the muscle and in an area of pain referral. Eur J Pain 2003; 7:267-76.

Leichsenring F. Randomized controlled versus naturalistic studies: a new research agenda. Bull Menninger Clin 2004; 68:137-51.

Linton SJ, Skevington SM. (1999). Epidemiology of Pain: Psychological factors (Seattle: IASP Press).

Lipton JA, Ship JA, Larach-Robinson D. Estimated prevalence and distribution of reported orofacial pain in the United States. J Am Dent Assoc 1993; 124:115-21.

List T, Leijon G, Svensson P. Somatosensory abnormalities in atypical odontalgia: A case-control study. Pain 2008; 139:333-41.

List T, Leijon G, Helkimo M, Öster A, Dworkin SF, Svensson P. Clinical findings and psychosocial factors in patients with atypical odontalgia: a case-control study. J Orofac Pain 2007; 21:89-98. 
List T, Leijon G, Helkimo M, Öster A, Svensson P. Effect of local anesthesia on atypical odontalgia - a randomized controlled trial. Pain 2006; 122:30614.

Lofthag-Hansen S, Huumonen S, Gröndahl K, Gröndahl HG. Limited conebeam CT and intraoral radiography for the diagnosis of periapical pathology. Oral Surg Oral Med Oral Pathol Oral Radiol Endod 2007; 103:114-9.

Magerl W, Krumova EK, Baron R, Tölle T, Treede RD, Maier C. Reference data for quantitative sensory testing $(\mathrm{QST})$ : refined stratification for age and a novel method for statistical comparison of group data. Pain 2010; 151:598-605.

Maier C, Baron R, Tölle TR, Binder A, Birbaumer N, Birklein F, Gierthmuhlen J, Flor H, Geber C, Huge V, Krumova EK, Landwehrmeyer GB, Magerl W, Maihofner C, Richter H, Rolke R, Scherens A, Schwarz A, Sommer C, Tronnier V, Uceyler N, Valet M, Wasner G, Treede RD. Quantitative sensory testing in the German Research Network on Neuropathic Pain (DFNS): somatosensory abnormalities in 1236 patients with different neuropathic pain syndromes. Pain 2010; 150:439-50.

Maixner W, Fillingim R, Booker D, Sigurdsson A. Sensitivity of patients with painful temporomandibular disorders to experimentally evoked pain. Pain 1995; 63:341-51.

Marbach JJ, Raphael KG. Phantom tooth pain: a new look at an old dilemma. Pain Med 2000; 1:68-77.

Marbach JJ, Hulbrock J, Hohn C, Segal AG. Incidence of phantom tooth pain: an atypical facial neuralgia. Oral Surg Oral Med Oral Pathol 1982; 53:1903 .

Marks LE. Spatial summation in relation to the dynamics of warmth sensation. Int J Biometeorol 1971; 15:106-10.

Meh D, Denislic M. Quantitative assessment of thermal and pain sensitivity. J Neurol Sci 1994; 127:164-9.

Melis M, Lobo SL, Ceneviz C, Zawawi K, Al-Badawi E, Maloney G, Mehta N. Atypical odontalgia: a review of the literature. Headache 2003; 43:1060-74.

Melzack R. The short-form McGill Pain Questionnaire Pain 1987; 30:191-7.

Merskey H, Bogduk N. (1994). Classification of Chronic Pain - Descriptions of Chronic Pain Syndromes and Definition of Pain Terms (Seattle: IASP Press).

Mock D, Frydman W, Gordon AS. Atypical facial pain: a retrospective study Oral Surg Oral Med Oral Pathol 1985; 59:472-4. 
Nie H, Graven-Nielsen T, Arendt-Nielsen L. Spatial and temporal summation of pain evoked by mechanical pressure stimulation. Eur J Pain 2009; 13:592-9.

Nixdorf DR, Drangsholt MT, Ettlin DA, Gaul C, De Leeuw R, Svensson P, Zakrzewska JM, De Laat A, Ceusters W. Classifying orofacial pains: a new proposal of taxonomy based on ontology. J Oral Rehabil 2011; .

Nixdorf DR, Moana-Filho EJ, Law AS, McGuire LA, Hodges JS, John MT. Frequency of persistent tooth pain after root canal therapy: a systematic review and meta-analysis. J Endod 2010a; 36:224-30.

Nixdorf DR, Moana-Filho EJ, Law AS, McGuire LA, Hodges JS, John MT. Frequency of nonodontogenic pain after endodontic therapy: a systematic review and meta-analysis. J Endod 2010b; 36:1494-8.

Ohrbach R, Turner JA, Sherman JJ, Mancl LA, Truelove EL, Schiffman EL, Dworkin SF. The Research Diagnostic Criteria for Temporomandibular Disorders. IV: evaluation of psychometric properties of the Axis II measures. J Orofac Pain 2010; 24:48-62.

Ohrbach R, Larsson P, List T. The jaw functional limitation scale: development, reliability, and validity of 8 -item and 20 -item versions. J Orofac Pain 2008; 22:219-30.

Ohrbach R, Dworkin SF. Five-year outcomes in TMD: relationship of changes in pain to changes in physical and psychological variables. Pain 1998; 74:315-26.

Okeson JP, Bell WE. (2004). Bell's orofacial pains (Chicago: Quintessence Pub. Co.).

Olgart LM. Pain research using feline teeth. J Endod 1986; 12:458-61.

Patel S, Dawood A, Mannocci F, Wilson R, Pitt Ford T. Detection of periapical bone defects in human jaws using cone beam computed tomography and intraoral radiography. Int Endod J 2009; 42:507-15.

Pau AK, Croucher R, Marcenes W. Prevalence estimates and associated factors for dental pain: a review. Oral Health Prev Dent 2003; 1:209-20.

Pfaffenrath V, Rath M, Pollmann W, Keeser W. Atypical facial painapplication of the IHS criteria in a clinical sample. Cephalalgia 1993; 13 Suppl 12:84-8.

Pfau DB, Rolke R, Nickel R, Treede RD, Daublaender M. Somatosensory profiles in subgroups of patients with myogenic temporomandibular disorders and Fibromyalgia Syndrome. Pain 2009; 147:72-83.

Reid KJ, Harker J, Bala MM, Truyers C, Kellen E, Bekkering GE, Kleijnen J. Epidemiology of chronic non-cancer pain in Europe: narrative review of prevalence, pain treatments and pain impact. Curr Med Res Opin 2011; 27:449-62. 
Reit C, Petersson K (2010). In: Textbook of Endodontology, $2^{\text {nd }}$ Ed. (Oxford: Blackwell Munksgaard).

Riley JL, Robinson ME, Wise EA, Myers CD, Fillingim RB. Sex differences in the perception of noxious experimental stimuli: a meta-analysis. Pain 1998; 74:181-7.

Rolke R, Baron R, Maier C, Tölle TR, Treede RD, Beyer A, Binder A, Birbaumer N, Birklein F, Botefur IC, Braune S, Flor H, Huge V, Klug R, Landwehrmeyer GB, Magerl W, Maihofner C, Rolko C, Schaub C, Scherens A, Sprenger T, Valet M, Wasserka B. Quantitative sensory testing in the German Research Network on Neuropathic Pain (DFNS): standardized protocol and reference values. Pain 2006a; 123:231-43.

Rolke R, Magerl W, Campbell KA, Schalber C, Caspari S, Birklein F, Treede RD. Quantitative sensory testing: a comprehensive protocol for clinical trials. Eur J Pain 2006b; 10:77-88.

Rossman LE, Hasselgren G, and Wolcott JE. (2006). Pathways of the Pulp (St. Louis: Mosby Inc., Elsevier Inc.).

SBU, Swedish Council on Health Technology Assessment. (2010). Rotfyllning - en systematisk litteraturöversikt.

Schnurr RF, Brooke RI. Atypical odontalgia. Update and comment on longterm follow-up. Oral Surg Oral Med Oral Pathol 1992; 73:445-8.

Seltzer S, Hargreaves KM. (2002). Seltzer and Bender's Dental Pulp (Carol Stream: Quinessence Publishing Co. Inc.).

Simons DG, Travell J, Simons LS. (1999). Travell \& Simons' Myofascial Pain and Dysfunction (Baltimore: Williams \& Wilkins).

Sogur E, Baksi BG, Gröndahl HG, Lomcali G, Sen BH. Detectability of chemically induced periapical lesions by limited cone beam computed tomography, intra-oral digital and conventional film radiography. Dentomaxillofac Radiol 2009; 38:458-64.

Staud R, Vierck CJ, Robinson ME, Price DD. Spatial summation of heat pain within and across dermatomes in fibromyalgia patients and pain-free subjects. Pain 2004; 111:342-50.

Stone AA, Schwartz JE, Broderick JE, Shiffman SS. Variability of momentary pain predicts recall of weekly pain: a consequence of the peak (or salience) memory heuristic. Pers Soc Psychol Bull 2005; 31:1340-6.

Svensson P, Baad-Hansen L, Pigg M, List T, Eliav E, Ettlin D, Michelotti A, Tsukiyama Y, Matsuka Y, Jääskeläinen SK, Essick G, Greenspan JD, Drangsholt M, Special Interest Group on Orofacial Pain. Guidelines and recommendations for assessment of somatosensory function in oro-facial pain conditions - a taskforce report. J Oral Rehabil 2011; 38:366-94. 
Svensson P, Baad-Hansen L, Thygesen T, Juhl GI, Jensen TS. Overview on tools and methods to assess neuropathic trigeminal pain. J Orofac Pain 2004; 18:332-8.

Svensson P, Sessle BJ. (2004). Clinical Oral Physiology (Copenhagen: Quintessence Publishing Co. Ltd.).

Svensson P, Bjerring P, Arendt-Nielsen L, Kaaber S. Quantitative determinations of sensory and pain thresholds on human oral mucosa by argon laser stimulation. Pain 1992; 49:233-9.

Svensson P, Bjerring P, Arendt-Nielsen L, Kaaber S. Variability of argon laserinduced sensory and pain thresholds on human oral mucosa and skin. Anesth Prog 1991; 38:79-83.

Treede RD, Jensen TS, Campbell JN, Cruccu G, Dostrovsky JO, Griffin JW, Hansson P, Hughes R, Nurmikko T, Serra J. Neuropathic pain. Redefinition and a grading system for clinical and research purposes. Neurology 2008; 70:1630-5.

Tronstad L. (2009). Clinical endodontics: a textbook (Stuttgart; New York: Thieme).

Turk DC. The role of psychological factors in chronic pain. Acta Anaesthesiol Scand 1999; 43:885-8.

Turp JC. Atypical odontalgia - a little known phantom pain. Schmerz 2001; 15:59-64.

Ware JE Jr, Sherbourne CD. The MOS 36-item short-form health survey (SF36). I. Conceptual framework and item selection. Med Care 1992; 30:47383.

Watson CP, Watt VR, Chipman M, Birkett N, Evans RJ. The prognosis with postherpetic neuralgia. Pain 1991; 46:195-9.

Woda A, Pionchon P. A unified concept of idiopathic orofacial pain: clinical features. J Orofac Pain 1999; 13:172-84; discussion 185-95.

Wolf E, Nilner M, Petersson A, Petersson K. Long-term follow-up by means of a questionnaire of 109 patients with long-lasting orofacial pain. Swed Dent J 2002; 26:125-34.

Woolf CJ. Central sensitization: implications for the diagnosis and treatment of pain. Pain 2011; 152:2-15.

Zagury JG, Eliav E, Heir GM, Nasri-Heir C, Ananthan S, Pertes R, Sharav Y, Benoliel R. Prolonged gingival cold allodynia: a novel finding in patients with atypical odontalgia. Oral Surg Oral Med Oral Pathol Oral Radiol Endod 2011; 111:312-9.

Zakrzewska JM, and Hamlyn PJ. (1999). Epidemiology of Pain: Facial pain (Seattle: IASP Press). 
ISBN/ISSN 978-9 I-7 I O4-3 87-0/0348-6672

MALMÖ UNIVERSITY 20506 MALMÖ, SWEDEN WWW.MAH.SE 